\title{
Description of six new species of Xenorhina Peters, 1863 from southern Papua New Guinea (Amphibia, Anura, Microhylidae)
}

\author{
Rainer Günther ${ }^{1}$, Stephen Richards ${ }^{2}$ \\ 1 Museum für Naturkunde, Herpetology Department, Invalidenstr. 43, 10115 Berlin, Germany \\ 2 Herpetology Department, South Australian Museum, North Terrace, Adelaide, South Australia 5000, Australia \\ http://zoobank.org/FB92F5DF-7FC7-4F01-A1DD-8E85B6F5FE67 \\ Corresponding author: Rainer Günther (rainer.guenther@mfn.berlin)
}

Academic editor: Rafe Brown • Received 15 October 2020 • Accepted 1 June 2021 • Published 9 July 2021

\begin{abstract}
We describe six new species of the microhylid frog genus Xenorhina from the southern slopes of Papua New Guinea's central cordillera and adjacent lowlands, based on a combination of morphological (including osteology) and bioacoustic features. All of the new species are fossorial or terrestrial inhabitants of tropical rainforest habitats and belong to a group of Xenorhina having a single, enlarged odontoid spike on each vomeropalatine bone. Advertisement calls and habitat preferences are described for each species, one of which is amongst the smallest hitherto members of the genus. Description of these six species brings the total number of Xenorhina known to 40 and emphasises the importance of the high-rainfall belt that extends along the southern flanks of New Guinea's central cordillera as a hotspot of Melanesian amphibian diversity.
\end{abstract}

\section{Key Words}

acoustics, Asterophryinae, central cordillera, fossorial frogs, morphology, odontoid spike, rainforest, taxonomy

\section{Introduction}

Asterophryine microhylid frogs occur from mainland and insular southeast Asia eastwards through New Guinea to New Britain Island and northern Australia (Clulow and Swan 2018, Suwannapoom et al. 2018). The group reaches its greatest diversity in the New Guinea region, where many genera are endemic or near-endemic to the New Guinea mainland (Menzies 2006). Xenorhina Peters, 1863 is a moderately speciose genus of asterophryine microhylid frogs that currently contains 34 named species distributed across New Guinea and some nearby islands (Zweifel 1972, Blum and Menzies 1989, Günther and Richards 2005, Menzies 2006, Kraus 2011, Günther et al. 2020, Frost 2021). With the exception of three arboreal species, X. arboricola Allison \& Kraus, 2000, $X$. macrodisca Günther \& Richards, 2005 and $X$. varia Günther \& Richards, 2005, other members of the genus are fossorial or inhabit litter or subterranean burrows and have squat bodies, small, pointed heads, small eyes and short, robust limbs (Menzies and Tyler 1977, Blum and Menzies 1989). The genus Xenorhina includes two main groups: 1) species having one or two spikes on each vomeropalatine and 2) species lacking vomeropalatine spikes. The former group was previously recognised as a separate genus, Xenobatrachus Peters \& Doria, 1878 (e.g. Blum and Menzies 1989, Menzies 2006), but Kraus and Allison (2002) noted the lack of synapomorphies distinguishing Xenorhina from Xenobatrachus and suggested that the two genera may need to be combined. Frost et al. (2006) subsequently synonymised Xenobatrachus with Xenorhi$n a$ (the older available name), based on molecular evidence, a move supported by Köhler and Günther (2008).

The monophyly of Xenorhina + Xenobatrachus is now well supported (de Sa et al. 2012, Peloso et al. 2015, Rivera et al. 2017), but the relationships of Xenorhina to other asterophryine genera remain poorly resolved. For example, molecular studies by Köhler and Günther (2008) and Pyron and Wiens (2011) concluded that Xenorhina is closely related to Asterophrys and some Callulops, while 
Rivera et al. (2017) found that Xenorhina is the sister taxon to Callulops, Mantophryne and Hylophorbus.

In this paper, we describe six new Xenorhina that belong to the group of species with enlarged vomeropalatine spikes. They were collected from localities within and adjacent to the high-rainfall belt extending along the southern flanks of New Guinea's central cordillera (McAlpine et al. 1983), a region that has previously been reported to support a diverse amphibian fauna (Hyndman and Menzies 1990, Richards and Günther 2019). Description of these frogs brings to 40 the number of recognised Xenorhina, making it the third most speciose microhylid genus in the New Guinea region after Oreophryne (61 species) and Cophixalus (48 species) (Richards and Günther 2019, Frost 2020). It also reinforces the importance of the extensively forested southern flanks of Papua New Guinea's central cordillera as a hotspot of Melanesian amphibian diversity.

\section{Material and methods}

Fieldwork was conducted in tropical rainforest habitats along the southern flanks of Papua New Guinea's central cordillera. Most frogs were located at night by their advertisement calls. Representative specimens were photographed in life and voucher animals were euthanised in an aqueous chlorobutanol solution (Gamble 2014) and subsequently fixed in $10 \%$ formalin. All specimens were transferred to $70 \%$ ethanol within two days of fixation. Descriptions follow a template developed for taxonomic treatments of New Guinea microhylid frogs, including Xenorhina (e.g. Günther et al. 2014, Günther et al. 2020). We adopt the biological species concept of E. Mayr (1963 and elsewhere), placing emphasis on reproductive isolation and we treat morphological, osteological and ethological (acoustic) differences as expressions of genetic differences that are large enough to prevent exchange of genes between the populations concerned. Our approach follows that of other taxonomic studies of this genus (Zweifel 1972, Blum and Menzies 1989, Kraus and Allison 2002, Günther et al. 2014).

The following measurements were taken with a digital calliper $(>10 \mathrm{~mm})$ or with a binocular dissecting microscope, fitted with an ocular micrometer $(<10 \mathrm{~mm})$ to the nearest $0.1 \mathrm{~mm}$ from preserved specimens using protocols for microhylid frogs adopted previously (e.g. Günther et al. 2014): SUL - snout-urostyle length from tip of snout to posterior tip of urostyle (SUL is sufficiently similar to SVL that, where relevant, we compare our SUL measurements with SVLs presented for members of the genus in some papers); TL - tibia length: external distance between knee and tibio-tarsal articulation (referred to herein also as "shank"); TaL - length of tarsus: external distance between tibio-tarsal and tarsal-metatarsal joints when held at right angles; T4L - length of $4^{\text {th }}$ toe: from tip of toe to proximal end of inner metatarsal tubercle; T4D - transverse diameter of disc of $4^{\text {th }}$ toe; T1D - transverse diameter of disc of first toe; F3L - length of $3^{\text {rd }}$ finger: from tip of $3^{\text {rd }}$ finger to proximal edge of palm; F3D - transverse diameter of disc of $3^{\text {rd }}$ finger; F1D - transverse diameter of disc of $1^{\text {st }}$ finger; HL - head length, from tip of snout to posterior margin of tympanum; HW - head width, taken across the tympana; SL - snout length, from an imaginary line connecting the centres of the eyes to tip of the snout; EST - distance from anterior corner of orbital opening to tip of snout; END - distance from anterior corner of orbital opening to centre of naris; IND - internarial distance between centres of nares; ED - eye diameter, from anterior to posterior corner of orbital opening; TyD - horizontal diameter of tympanum. Measurements are presented as arithmetic means \pm standard deviation and range. Statistical calculations were done with the programme Statgraphics Centurion Version 15.2.14 (Statpoint Technologies, Inc., Warrenton, Virginia, USA). All p-values are calculated by the non-parametric Mann-Whitney (Wilcoxon) Test for comparison of medians. Osteological features were determined by superficial dissection.

Sex was determined mainly by observations of calling in the field and/or the presence of vocal slits or testes (males) or absence of vocal slits and/or presence of eggs (females). Advertisement calls were recorded under natural conditions with a Sony WM-D6C Professional Walkman tape recorder, a Marantz PMD-661 or an Edirol R09 digital recorder and a Sennheiser ME66 shotgun microphone and analysed with the sound-analysis package Avisoft-SAS Lab Pro. Air temperatures adjacent to calling males were recorded using a rapid-reading digital thermometer. Terminology and acoustic analysis procedures mostly follow Köhler et al. (2017). All of the species described here produce calls in groups, which are separated from other groups by periods of silence that are much longer than the inter-call intervals and within which calls are repeated at regular intervals. As such, they meet the definition of a "call series" from Köhler et al. (2017). For all species, each call within a series comprises a single unpulsed note ( use the term "call" in preference to "note" throughout to provide consistency. Measurements of call parameters are presented predominantly as range and mean \pm standard deviation.

Colour of animals in life was described from digital photographs and of preserved specimens from direct observations. Most colours were determined according to a colour matching system that is created and administrated by the German RAL GmbH (RAL non-profit LLC). It should be stressed, however, that in many cases it was impossible to find an exact match between observed colours and RAL colour numbers. In those cases, the most similar RAL number was chosen.

Specimens are stored in the South Australian Museum, Adelaide, Australia (SAMA) and the Museum für Naturkunde, Berlin, Germany (ZMB). Paratypes for most species will also be repatriated to the Papua New Guinea National Museum, Port Moresby, Papua New 
Guinea (PNGNM). Abbreviations for other institutions mentioned are: American Museum of Natural History, New York, U.S.A. (AMNH); Bernice P. Bishop Museum, Hawaii, U.S.A. (BPBM); Institut Royal des Sciences Naturales de Belgique, Brussels (IRSNB); Museo Civico di Storia Naturale di Genova, Genoa, Italy (MSNG); Museum of Comparative Zoology, Harvard, U.S.A. (MCZ); Museum Zoologicum Bogoriense, Cibinong, Indonesia (MZB); National Museum of Natural History, now Naturalis Biodiversity Center, Leiden, The Netherlands (RMNH); University of Papua New Guinea, Port Moresby (UP); Zoological Museum Amsterdam, now Naturalis Biodiversity Center, Leiden, The Netherlands (ZMA). SJR refers to the original field collection tag of Stephen Richards.

Specimens examined for comparative purposes are listed in Appendix 1. Additional morphometric and other data were extracted from original species descriptions and/or recompiled treatises, particularly Zweifel (1972), Blum and Menzies (1989), Kraus and Allison (2002) and Menzies (2006).

\section{Systematics}

Specimens were assigned to the genus Xenorhina on the basis of the following combination of features: jaw symphygnathine; clavicles and procoracoids absent; each vomeropalatine bone with elongated odontoid spike; body squat, head small, triangular, with small eyes; cutaneous tubercles present dorsolaterally, absent on eyelids; tips of toes 2-5 expanded, with circum-marginal grooves; life style subterrestrial.

\section{Xenorhina lacrimosa sp. nov.}

http://zoobank.org/D78F9340-1032-4D34-976A-B91C7001CC1C

Holotype. SAMA R71648 (SJR 14203), adult male, from Rentoul River, Western Province, Papua New Guinea (6.4355 ${ }^{\circ} \mathrm{S}, 142.5615^{\circ} \mathrm{E} ; 380 \mathrm{~m}$ a.s.1.), collected on $10-08-$ 2014 by S.J. Richards.

Paratypes. SAMA R71647 (SJR10389), female with ripe eggs, ZMB 91129 (SJR10417) male, Camp 2, upper Strickland River basin, Western Province, Papua New Guinea $\left(5.9018^{\circ} \mathrm{S}, 142.4360^{\circ} \mathrm{E}\right.$; $950 \mathrm{~m}$ a.s.1.), collected by S.J. Richards on 18-02-2008 and 20-02-2008, respectively; ZMB 91130 (SJR10466) male, Camp 1, upper Strickland River basin, Western Province, Papua New Guinea $\left(5.8078^{\circ} \mathrm{S}, 142.3083^{\circ} \mathrm{E} ; 215 \mathrm{~m}\right.$ a.s.1.), collected by S.J. Richards on 26-03-2008; SAMA R65069 (SJR10902) and R65070 (SJR10949), males, R65071 (SJR10963), (subadult?) female with scarcely developed eggs and R65072 (SJR10985), juvenile, Gugusu Camp, Muller Range, Western Province $\left(5.7290^{\circ} \mathrm{S}, 142.2630^{\circ} \mathrm{E}\right.$; $515 \mathrm{~m}$ a.s.1.), all collected by S.J. Richards and C. Dahl between 7-9-09-2009.
Referred specimens. SAMA R71649, R71650 (SJR2577, 2582), PNGNM (SJR2571), adult males, Herowana, Eastern Highlands Province, Papua New Guinea $\left(6.6220^{\circ} \mathrm{S}, 145.1962^{\circ} \mathrm{E} ; 1,400 \mathrm{~m}\right.$ a.s.1.), collected by S.J. Richards between 20 and 24-11-2001.

Diagnosis. This species of Xenorhina is characterised by the unique combination of: medium size (SUL of five males 34.5-41.0 $\mathrm{mm}$ ); vomeropalatines each with one long and acuminate spike; legs moderately long (TL/SUL 0.42-0.46); all fingers without and all toes with expanded discs; eye-naris distance greater than internarial distance (END/IND 1.18-1.48); tympanum diameter smaller than or equal to that of eye (TyD/ED 0.75-1.00); dorsal surfaces in life different tones of brown or blue or a mixture of these colours; ventral surfaces different tones of orange with irregular whitish spots or mouse grey (RAL 7005) with whitish spots and reticulations; advertisement calls uttered in series containing 7-12 single, mournful "hoots" separated by long intervals of about five seconds.

Description of the holotype. Measurements are summarised in Table 1, a dorsolateral view in life is shown in Fig. 1a and ventral surfaces in life in Fig. 1b. Head broader than long (HL/HW 0.74); snout acuminate from above and below, distinctly protruding in profile; tongue very broad, only its lateral and posterior edges free; prepharyngeal ridge with five roundish denticles; left vomerine spike very well developed, right spike present, but malformed; loreal region oblique, no canthus rostralis; nostrils near tip of snout, directed more lateral than dorsal, visible from above, but not from below; eye-naris distance greater than internarial distance (END/IND 1.18); tympanum visible in life and preservative, its diameter slightly less than that of eye (TyD/ED 0.87); supratympanic fold weakly expressed, extending from behind eye to insertion of fore leg; shank short (TL/SUL 0.42); fingers moderately short, not webbed; tips of all fingers with circum-marginal grooves, all not wider than penultimate phalanges; relative lengths of fingers $3>4=1$ $=2$ (Fig. 1c); all toe tips with circum-marginal grooves and wider than penultimate phalanges; toes not webbed, relative lengths $4>3>5>2>1$ (Fig. 1d); plantar and palmar tubercles (with exception of prominent, oval inner metatarsal tubercle; Fig. 1d), as well as subarticular tubercles scarcely visible. Body laterally with numerous distinct tubercles in life, less prominent in preservative; dorsal surfaces of limbs and middle of dorsum with fewer tubercles, all ventral surfaces smooth; tip of snout with several tiny elevations (especially on underside).

In life, dorsal surfaces of head and anterior portion of body and fore limbs, uniform bluish-brown; remaining dorsal surfaces and flanks a mixture of saffron-yellow (RAL 1017) and blue-grey; tubercles with brown bases and whitish apices concentrated on flanks; body dorsally with light yellow mid-dorsal line that continues on to hind legs; lumbar region with light yellow semi-circular spot (Fig. 1a); vent and adjacent region enclosed within 

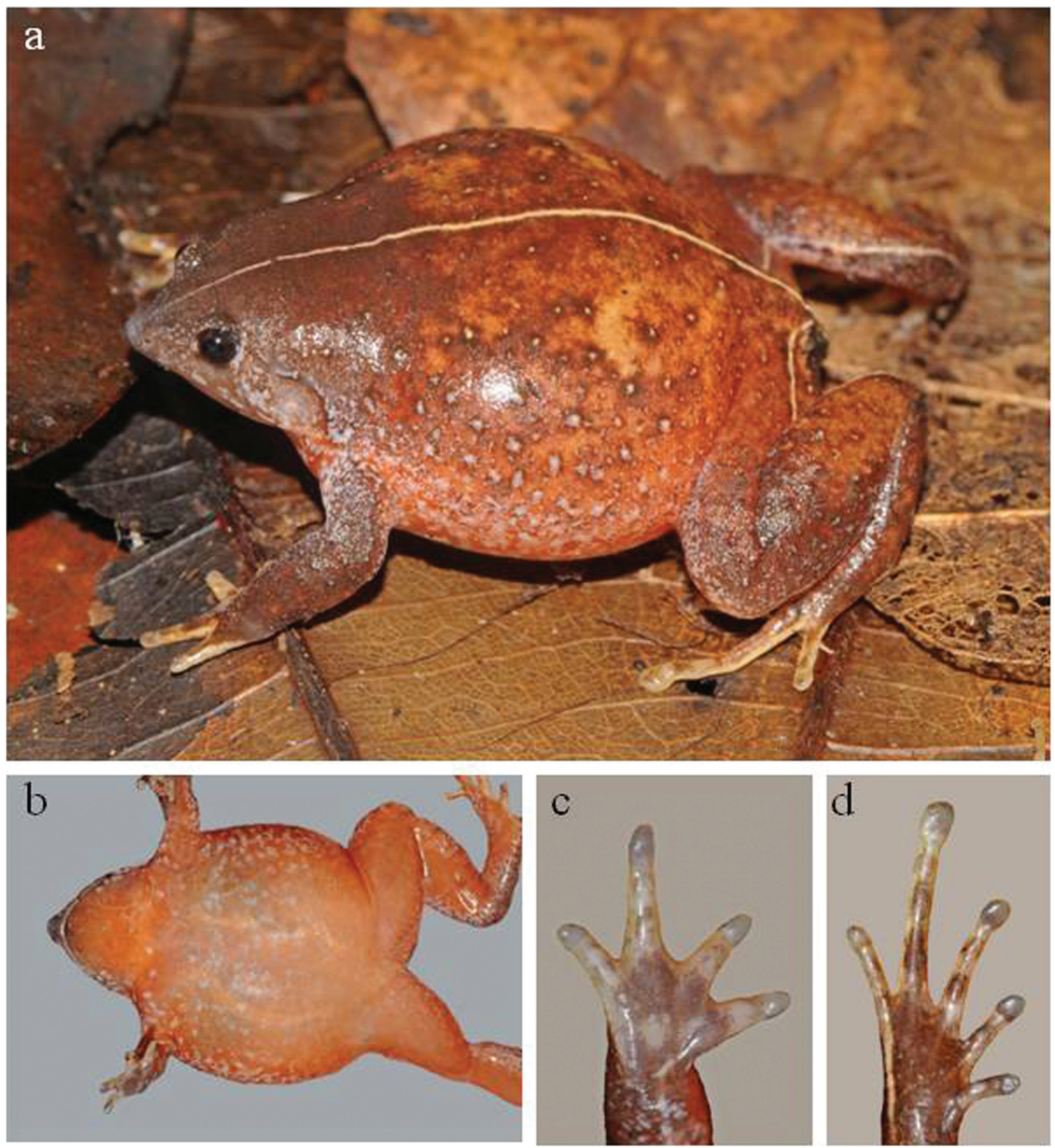

Figure 1. Holotype (SAMA R71648) of Xenorhina lacrimosa sp. nov. in life: (a) Dorsolateral view; (b) Ventral view; (c) Volar view of right hand; (d) Thenar view of right foot.

dark brown triangular patch; iris blackish with barely visible golden reticulation; plantar and ventral surfaces of toes predominantly brown, palms and ventral surfaces of fingers predominantly grey and cream; throat, chest, abdomen and ventral surfaces of extremities deep orange (RAL 2011), with some whitish spots (Fig. 1b).

In preservative, dorsal surfaces of head, anterior back and fore limbs signal brown (RAL 8002); other dorsal surfaces ivory with diffuse brownish smears, tubercles with terra brown (RAL 8028) bases and whitish apices; ventral surfaces light ivory (RAL 1015); ivory lumbar spot on left side more clearly pronounced than on right.
Morphological variation. Measurements and proportions of most paratypes show limited variation (Table 1). An exception is a juvenile (SAMA R65072) measuring $16.6 \mathrm{~mm}$ SUL that exhibits some major deviations in proportions from the remainder of the type series. As these differences are almost certainly due to allometry, measurements of this specimen are disregarded in Table 1 . Males and females have the same body size, although some ratios of the adult female (SAMA R71647 differ to a negligible degree (Table 1). The smallest specimen in the series is the just-mentioned adult female with an SUL of "only" $34.3 \mathrm{~mm}$ that contains ripe ovarian eggs; 
the largest specimen in the series is a male (ZMB 91130) with an SUL of $41.0 \mathrm{~mm}$.

Colour of paratypes in life varies considerably. Dorsal surfaces may be uniform blue-brown (SAMA R65070, Fig. 2a), uniform light red-orange similar to RAL 2008 (ZMB 91129, Fig. 2b), bluish on head and lower flanks, but reddish-brown on back and dorsal extremities (ZMB 91130, Fig. 2c) or dark brown with bluish hue on head, body and thighs, but beige on fore limbs, shanks and tarsi (SAMA R71647, Fig. 2d). Colour of ventral surfaces is also highly variable. Some specimens are uniform deep orange or traffic orange (RAL 2009) interspersed with scattered irregular whitish spots (SAMA R65070, Fig. 2e); others are more extensively spotted (ZMB 91129, Fig. 2f) or exhibit a mixture of whitish, orange and brown spots, but with throat and thighs more or less uniform traffic orange (SAMA R65071, Fig. 2g); others exhibit grey-brown ground colour with many irregular whitish spots, some of them interspersed with small irregular red patches (SAMA R71647, Fig. 2h) .

In preservative dorsal surfaces of three specimens predominantly violet, of two specimens copper brown, of one specimen beige and of the juvenile specimen beige-brown; ventral surfaces of three specimens almost completely light ivory, of the four other specimens a light ivory ground colour with a brown-beige pattern of various extent. All paratypes, except SAMA R71647, have a light ivory mid-dorsal line and all specimens including the juvenile have a greyish snout tip. None of the paratypes has a clearly pronounced lumbar spot in life or in preservative.

Distribution and ecological notes. Most records of Xenorhina lacrimosa sp. nov. are from lowland and foothill forest in south-central Papua New Guinea (Fig. 8), where this species appears to have a broad distribution at altitudes ranging from near sea level around Kopi to at least $950 \mathrm{~m}$ a.s.1. We also refer several specimens from Herowana Village at $1,400 \mathrm{~m}$ a.s.1. (the most easterly location in Fig. 8) to this species pending confirmation of genetic relationships. Males called at night, normally after rain, either from within the leaf litter on the forest floor or down to several centimetres depth in the humus layer beneath the litter.

Table 1. Body measurements and body ratios of the type series of Xenorhina lacrimosa sp. nov. SAMA R71648 is the male holotype, others are paratypes. All measurements in $\mathrm{mm}$; for explanation of abbreviations see "Material and methods"; $\mathrm{M}=$ male, $\mathrm{F}=$ female, $\mathrm{sa}=$ subadult.

\begin{tabular}{|c|c|c|c|c|c|c|c|c|}
\hline Reg.-No. & SAMA R71647 & ZMB 91129 & ZMB 91130 & SAMA R71648 & SAMA R65069 & SAMA R65070 & SAMA R65071 & Mean \pm SD \\
\hline Sex & $\mathrm{F}$ & $\mathrm{M}$ & $M$ & $\mathrm{M}$ & $\mathrm{M}$ & $M$ & sa F & \\
\hline SUL & 34.3 & 36.9 & 41.0 & 36.2 & 37.3 & 34.5 & 35.1 & $36.47 \pm 2.30$ \\
\hline TL & 15.0 & 17.0 & 18.6 & 15.3 & 15.8 & 15.3 & 15.4 & $16.06 \pm 1.30$ \\
\hline TaL & 10.0 & 11.8 & 12.6 & 10.2 & 11.0 & 10.3 & 9.9 & $10.83 \pm 1.03$ \\
\hline T4L & 16.9 & 17.6 & 19.1 & 15.2 & 16.9 & 15.1 & 15.5 & $16.61 \pm 1.46$ \\
\hline T4D & 1.3 & 1.6 & 1.5 & 1.3 & 1.5 & 1.4 & 1.3 & $1.41 \pm 0.12$ \\
\hline T1D & 0.8 & 1.0 & 1.0 & 0.9 & 1.0 & 0.9 & 0.9 & $0.93 \pm 0.076$ \\
\hline F3L & 6.3 & 8.1 & 9.1 & 7.0 & 7.8 & 6.7 & 7.2 & $7.46 \pm 0.82$ \\
\hline F3D & 0.8 & 1.0 & 1.1 & 0.8 & 0.8 & 0.9 & 0.9 & $0.93 \pm 0.076$ \\
\hline F1D & 0.7 & 0.9 & 1.0 & 0.6 & 0.7 & 0.8 & 0.7 & $0.77 \pm 0.14$ \\
\hline $\mathrm{HL}$ & 9.5 & 10.4 & 12.0 & 9.7 & 11.2 & 10.1 & 10.3 & $10.46 \pm 0.87$ \\
\hline $\mathrm{HW}$ & 11.9 & 14.6 & 16.0 & 13.1 & 12.7 & 11.4 & 13.1 & $13.26 \pm 1.58$ \\
\hline END & 2.5 & 3.0 & 3.6 & 2.6 & 3.5 & 3.4 & 3.0 & $3.09 \pm 0.43$ \\
\hline IND & 1.7 & 2.3 & 2.6 & 2.2 & 2.4 & 2.3 & 2.2 & $2.24 \pm 0.28$ \\
\hline SL & 4.0 & 4.3 & 5.1 & 4.2 & 5.0 & 4.7 & 4.7 & $4.57 \pm 0.42$ \\
\hline EST & 3.6 & 4.1 & 5.0 & 3.5 & 4.6 & 4.7 & 4.2 & $4.24 \pm 0.56$ \\
\hline ED & 2.4 & 2.7 & 2.8 & 2.3 & 2.4 & 2.2 & 2.1 & $2.41 \pm 0.25$ \\
\hline TyD & 2.4 & 2.5 & 2.1 & 2.0 & 2.1 & 1.8 & 1.9 & $2.11 \pm 0.25$ \\
\hline TL/SUL & 0.44 & 0.46 & 0.45 & 0.42 & 0.42 & 0.44 & 0.44 & $0.44 \pm 0.015$ \\
\hline TaL/SUL & 0.29 & 0.32 & 0.31 & 0.28 & 0.29 & 0.30 & 0.28 & $0.30 \pm 0.015$ \\
\hline T4L/SUL & 0.49 & 0.48 & 0.47 & 0.42 & 0.45 & 0.44 & 0.44 & $0.46 \pm 0.025$ \\
\hline T4D/SUL & 0.038 & 0.043 & 0.037 & 0.036 & 0.040 & 0.041 & 0.037 & $0.039 \pm 0.003$ \\
\hline T1D/SUL & 0.023 & 0.027 & 0.024 & 0.025 & 0.027 & 0.026 & 0.026 & $0.025 \pm 0.002$ \\
\hline F3L/SUL & 0.184 & 0.220 & 0.222 & 0.193 & 0.209 & 0.194 & 0.205 & $0.204 \pm 0.014$ \\
\hline F3D/SUL & 0.023 & 0.027 & 0.027 & 0.022 & 0.021 & 0.026 & 0.026 & $0.025 \pm 0.003$ \\
\hline F1D/SUL & 0.020 & 0.024 & 0.024 & 0.017 & 0.019 & 0.023 & 0.020 & $0.021 \pm 0.003$ \\
\hline T4D/F3D & 1.63 & 1.60 & 1.36 & 1.63 & 1.88 & 1.56 & 1.44 & $1.59 \pm 0.165$ \\
\hline T1D/F1D & 1.14 & 1.11 & 1.00 & 1.50 & 1.43 & 1.13 & 1.29 & $1.23 \pm 0.183$ \\
\hline HL/SUL & 0.28 & 0.28 & 0.29 & 0.27 & 0.30 & 0.29 & 0.29 & $0.29 \pm 0.009$ \\
\hline HW/SUL & 0.35 & 0.40 & 0.39 & 0.36 & 0.34 & 0.33 & 0.37 & $0.36 \pm 0.026$ \\
\hline $\mathrm{HL} / \mathrm{HW}$ & 0.80 & 0.71 & 0.75 & 0.74 & 0.88 & 0.89 & 0.79 & $0.79 \pm 0.069$ \\
\hline END/SUL & 0.073 & 0.081 & 0.088 & 0.072 & 0.094 & 0.099 & 0.085 & $0.085 \pm 0.010$ \\
\hline IND/SUL & 0.050 & 0.062 & 0.063 & 0.061 & 0.064 & 0.067 & 0.063 & $0.061 \pm 0.005$ \\
\hline END/IND & 1.47 & 1.30 & 1.38 & 1.18 & 1.46 & 1.48 & 1.36 & $1.38 \pm 0.109$ \\
\hline ED/SUL & 0.070 & 0.073 & 0.068 & 0.064 & 0.064 & 0.064 & 0.060 & $0.066 \pm 0.004$ \\
\hline TyD/SUL & 0.073 & 0.068 & 0.051 & 0.055 & 0.056 & 0.052 & 0.054 & $0.058 \pm 0.009$ \\
\hline TyD/ED & 1.00 & 0.93 & 0.75 & 0.87 & 0.88 & 0.82 & 0.90 & $0.88 \pm 0.079$ \\
\hline SL/SUL & 0.117 & 0.117 & 0.124 & 0.116 & 0.134 & 0.136 & 0.134 & $0.125 \pm 0.009$ \\
\hline EST/SUL & 0.105 & 0.111 & 0.122 & 0.097 & 0.123 & 0.136 & 0.120 & $0.116 \pm 0.013$ \\
\hline
\end{tabular}



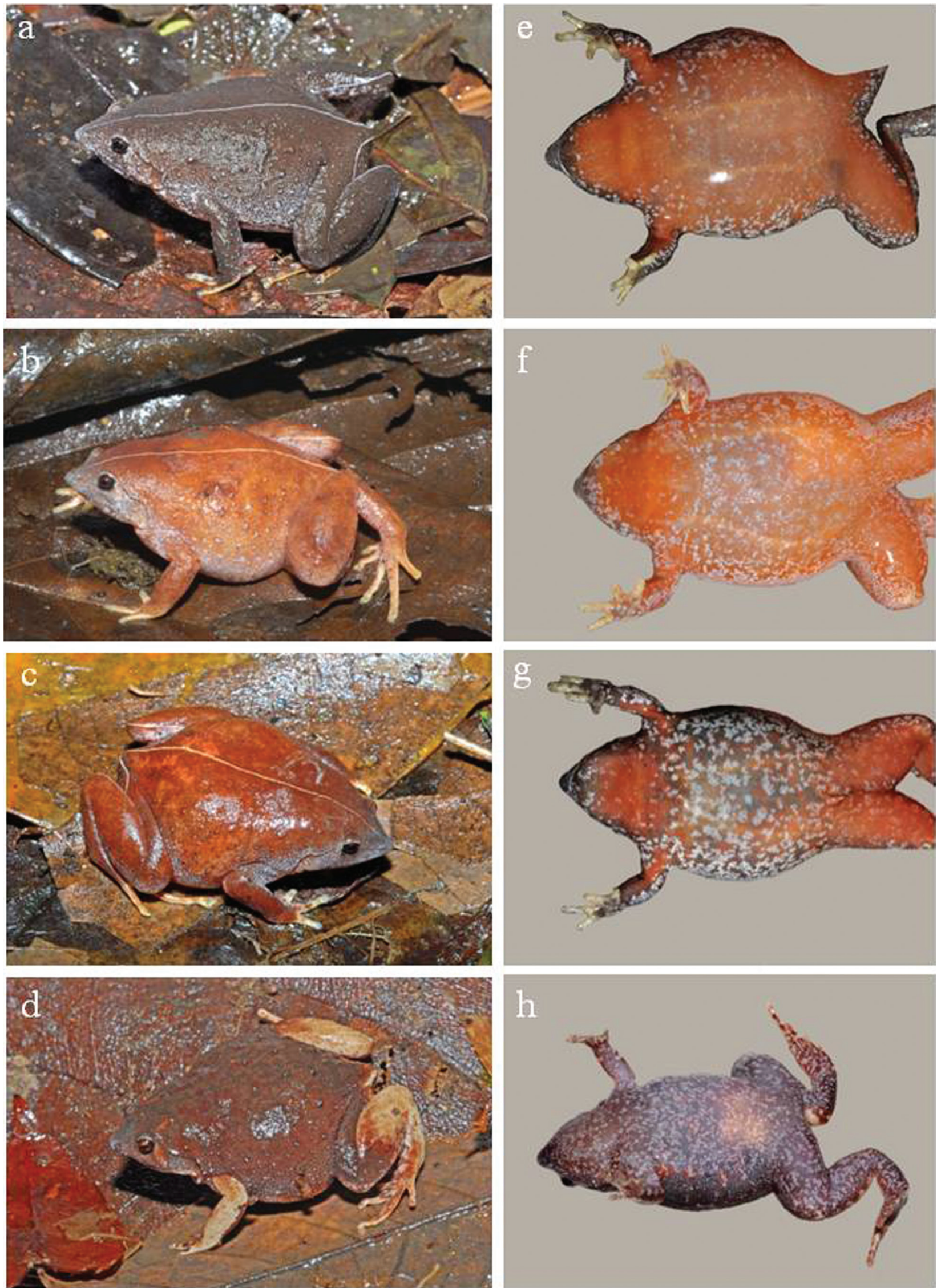

Figure 2. Xenorhina lacrimosa sp. nov. paratypes in life. Dorsolateral views: (a) SAMA R65070; (b) ZMB 91129; (c) ZMB 91130; (d) SAMA R71647. Ventral views: (e) SAMA R65070S; (f) ZMB 91129; (g) SAMA R65071; (h) SAMA R71647. 
Vocalisation. One call series from SAMA R71648 (holotype), one from ZMB 91129 (paratype), one from SAMA R65069 (paratype) and four from ZMB 91130 (paratype) recorded at air temperatures of $21.2-25.5^{\circ} \mathrm{C}$ were analysed. Each call is a single, unpulsed mournful note that is always produced in a series, during which both volume and pitch increase gradually between first and last call (Fig. 3a). Despite some variation in recording temperature, all recorded calls are extremely similar, so they were pooled for analyses. Call series last 26.4-60.4 s (mean $40.0 \pm 11.8 \mathrm{~s}, \mathrm{n}=7$ ), with $7-12$ calls/series (mean $9.0 \pm$ $2.2, \mathrm{n}=7$ ) produced at a rate of $0.20-0.27$ calls/s (mean
$0.23 \pm 0.02$ ). Call length is $141-231 \mathrm{~ms}$ (mean $193.5 \pm$ $19.1 \mathrm{~ms}, \mathrm{n}=63$ ) and first and last call in a series are often the shortest; inter-call interval length is $2.8-8.0 \mathrm{~s}$. (mean $4.8 \pm 1.0 \mathrm{~s}, \mathrm{n}=56$ ). Calls start abruptly at high amplitude that rises quickly to a maximum, then decreases gradually until termination of call (Fig. 3b). All calls have 5-7 harmonics (Fig. 3c and 3d)). Dominant frequency may be carried by a second harmonic (i.e. first two calls of series from holotype, with peak at $1.2 \mathrm{kHz}$ ) or by first harmonic (all other calls, with peaks increasing from $0.7 \mathrm{kHz}$ in third call to $0.8 \mathrm{kHz}$ in last call in the series. Frequency declines at end of each call in second half of series (Fig. 3c).
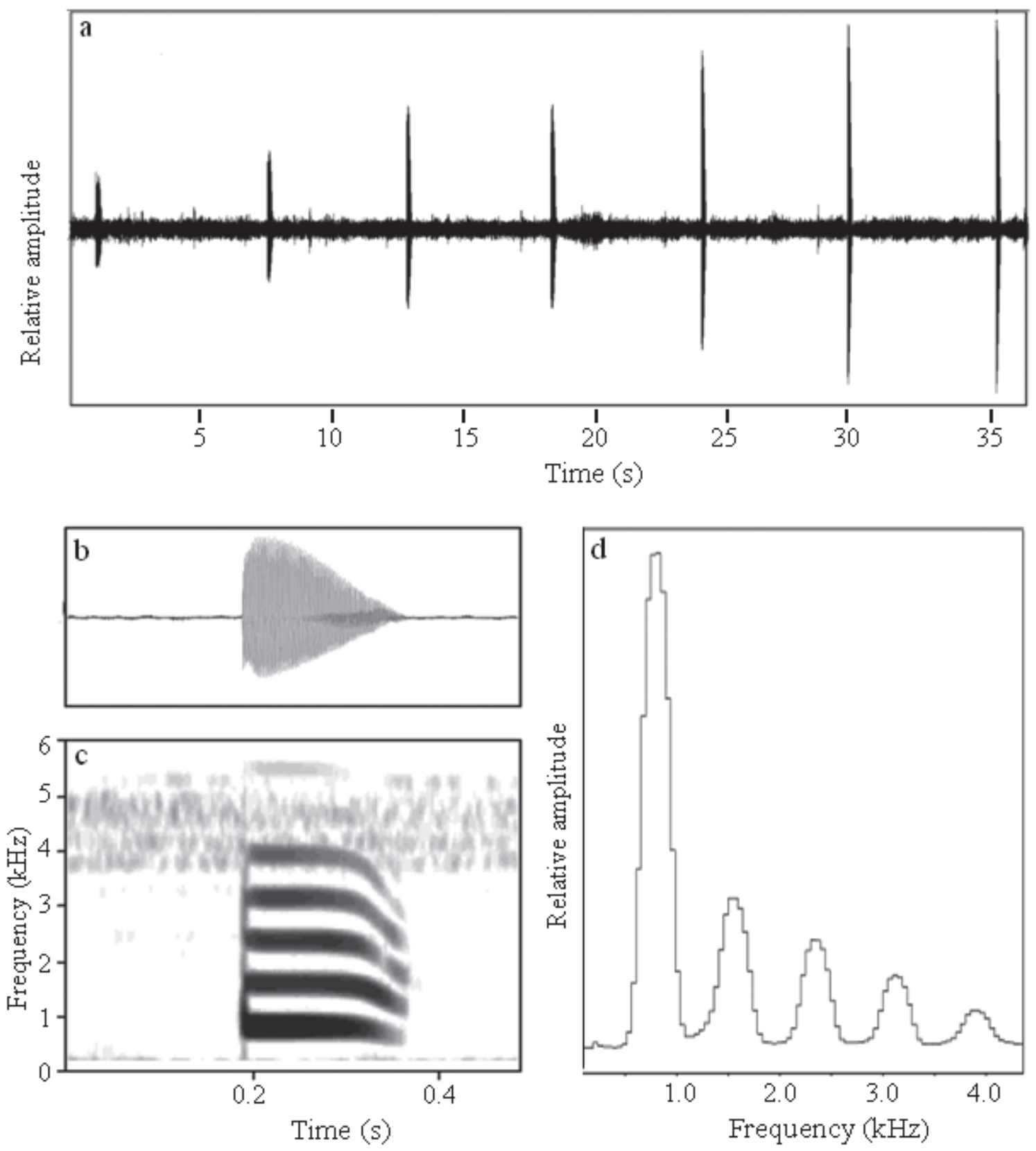

Figure 3. (a) Oscillogram of a complete advertisement call series with seven calls from the holotype of Xenorhina lacrimosa sp. nov.; (b) oscillogram and (c) spectrogram of the penultimate call of the call series shown on Fig. 3a; (d) amplitude spectrum of the call on (b.) and (c.). 
Etymology. The specific epithet lacrimosa is a Latin adjective in female gender; translated literally it means "tearful", but it is also translated as "lamentable voice" and refers to the mournful sounding advertisement call of the new species.

Comparisons with other species. We compare Xenorhina lacrimosa sp. nov. with all congeners of a similar size (SUL 30-43 mm) that have a single spike on each vomeropalatine bone.

Xenorhina fuscigula (Blum \& Menzies, 1989) has hind legs shorter (TL/SVL $<0.40$ vs. $>0.40$ in Xenorhina lacrimosa sp. nov.), eye-naris distance shorter (END/ SVL 0.064-0.074 vs. 0.072-0.099), inner metatarsal tubercle absent (vs. present), ventral surfaces black (vs. orange-red or grey-brown) and call consisting of a single long note (vs. a series of 7-12 notes $=$ calls).

Xenorhina huon (Blum \& Menzies, 1989) is smaller (SUL to $32 \mathrm{~mm}$ vs. 34.3-41.0 mm), with hind legs shorter $(\mathrm{TL} / \mathrm{SUL}<0.40$ vs. $>0.40)$, internarial distance greater (0.064-0.081 vs. 0.050-0.067), eyes larger (ED/ SVL $0.070-0.091$ vs. 0.060-0.073) and ventral surfaces with dark flecking (vs. ventral surfaces with no or sparse brownish reticulation).

Xenorhina subcrocea (Menzies \& Tyler, 1977) is smaller (SUL 30.5-33.3 mm vs. 34.3-41.0 mm), with hind legs longer (TL/SVL $>0.46$ vs. $<0.46$ in Xenorhina lacrimosa sp. nov.) and ventral surfaces with dark reticulation (vs. without dark reticulation); call length is shorter 64-69 ms (vs. 141-231 ms), with inter-call interval also much shorter (154-285 ms vs. 2.8-8.0 s).

Xenorhina zweifeli (Kraus \& Allison, 2002) is about the same size and has similar body ratios. It differs by having a conspicuous dark brown supratympanic stripe (vs. absent in Xenorhina lacrimosa sp. nov.) and in several aspects of its advertisement calls. Xenorhina zweifeli utters single calls at irregular intervals, with two or three calls sometimes produced in quick succession (Kraus and Allison 2002), during both day and early evening. In contrast, Xenorhina lacrimosa sp. nov. always produces calls in discrete series of at least seven relatively evenly spaced calls of increasing pitch and volume; calls are never produced in quick succession and males always call at night. Other differences include: mean length of calls produced by holotype of X. zweifeli is $310 \mathrm{~ms}$ (Kraus and Allison 2002) (vs. mean length of calls from Xenorhina lacrimosa sp. nov. $194 \mathrm{~ms}$ ); the fundamental frequency of zweifeli calls is at $610 \mathrm{~Hz}$ and dominant frequency at $1910 \mathrm{~Hz}$ (third harmonic), (vs. fundamental and dominant frequency of Xenorhina lacrimosa sp. nov., both at $800 \mathrm{~Hz}$ ); amplitude of $X$. zweifeli calls rises more slowly than that of lacrimosa calls and all harmonics are frequency modulated, with pitch decreasing during entire length of call (vs. frequency modulation only occurring at end of harmonics in Xenorhina lacrimosa sp. nov. calls). Moreover, X. zweifeli occurs only on two mountain ranges in northern Papua New Guinea, while Xenorhina lacrimo$s a$ sp. nov. lives predominantly in the lowlands and foothills of southern Papua New Guinea. Therefore, the known distributions of the two species are separated by a major biogeographic barrier, New Guinea's central cordillera.

\section{Xenorhina perexigua sp. nov.}

http://zoobank.org/96AFDF65-2D60-4245-AB15-BDA2728A6A88

Holotype. SAMA R71645 (SJR 10418), adult male, from Camp 2, upper Strickland River basin, Western Province, Papua New Guinea (5.9018 $\mathrm{S}, 142.4360^{\circ} \mathrm{E} ; 950 \mathrm{~m}$ a.s.1.), collected by S.J. Richards on 20-02-2008

Diagnosis. This species of Xenorhina is characterised by the unique combination of: very small body size (SUL of the only adult male $16.7 \mathrm{~mm}$ ); vomeropalatines each with a single triangular spike; legs moderately long (TL/SUL 0.46); all fingers and first toe without and toes 2-5 with expanded discs; eye-naris distance greater than internarial distance (END/IND 1.27); tympanum smaller than eye (TyD/ED 0.77); dorsal surfaces in life beige brown (RAL 8024) with darker areas on upper flanks, in middle of back and on neck; lower flanks with whitish spots and reticulations and some irregular dark brown flecks; supratympanic area with dark brown fleck; ventral surfaces off-white with extensive blackish-brown reticulation. Advertisement calls in series containing about 30 soft "popping" calls of 30-40 ms duration, produced at a rate of $6.8-6.9$ calls $/ \mathrm{s}$.

Description of the holotype. Measurements and ratios are presented in Table 2. Body squat (Fig. 4a and b), head broader than long (HL/HW 0.84); snout strongly acuminate from above and below and protruding in profile; tongue broad, only its lateral and posterior edges free; prepharyngeal ridge without denticles; a single tri-

Table 2. Body measurements and body ratios of the male holotype (SAMA R71645) of Xenorhina perexigua sp. nov.. All measurements in $\mathrm{mm}$; for explanation of abbreviations see "Material and methods".

\begin{tabular}{|c|c|c|c|}
\hline Reg.-No. & SAMA R71645 & Reg.-No. & SAMA R71645 \\
\hline SUL & 16.7 & TL/SUL & 0.46 \\
\hline TL & 7.6 & TaL/SUL & 0.30 \\
\hline TaL & 5.0 & T4L/SUL & 0.45 \\
\hline T4L & 7.5 & T4D/SUL & 0.036 \\
\hline T4D & 0.6 & T1D/SUL & 0.018 \\
\hline T1D & 0.3 & F3L/SUL & 0.186 \\
\hline F3L & 3.1 & F3D/SUL & 0.021 \\
\hline F3D & 0.35 & F1D/SUL & 0.012 \\
\hline F1D & 0.2 & T4D/F3D & 1.71 \\
\hline $\mathrm{HL}$ & 4.6 & T1D/F1D & 1.50 \\
\hline HW & 5.5 & HL/SUL & 0.28 \\
\hline END & 1.4 & HW/SUL & 0.33 \\
\hline IND & 1.1 & $\mathrm{HL} / \mathrm{HW}$ & 0.84 \\
\hline SL & 2.2 & END/SUL & 0.084 \\
\hline EST & 2.0 & IND/SUL & 0.066 \\
\hline ED & 1.3 & END/IND & 1.27 \\
\hline \multirow[t]{5}{*}{ TyD } & 1.0 & ED/SUL & 0.078 \\
\hline & & TyD/SUL & 0.060 \\
\hline & & TyD/ED & 0.77 \\
\hline & & SL/SUL & 0.132 \\
\hline & & EST/SUL & 0.120 \\
\hline
\end{tabular}



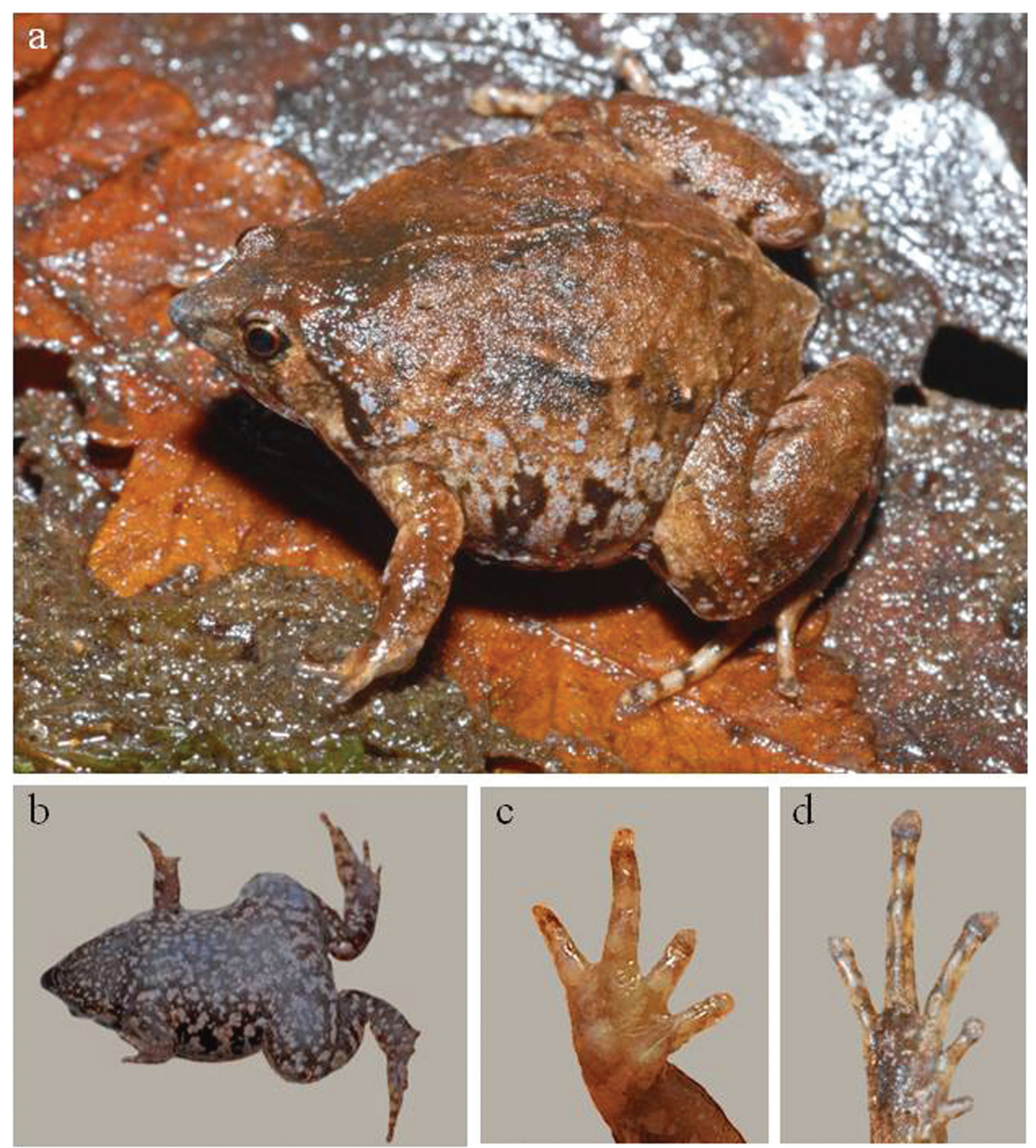

Figure 4. Holotype (SAMA R71645) of Xenorhina perexigua sp. nov. in life: (a) Dorsolateral view; (b) Ventral view; (c) Volar view of right hand; (d) Thenar view of right foot.

angular spike of moderate size on each vomeropalatine; loreal region oblique, no canthus rostralis; nostrils near tip of snout, directed dorsolaterally, visible from above, but not from below; eye-naris distance greater than internarial distance (END/IND 1.27); greater part of tympanum visible in life and preservative, its diameter smaller than that of eye (TyD/ED 0.77); supratympanic fold short, not contacting posterior edge of eye and not reaching insertion of fore leg; shank of moderate length (TL/SUL 0.46); fingers moderately short, not webbed; tips of fingers not wid- er than penultimate phalanges, all with circum-marginal grooves that extend along entire length of digits, relative lengths of fingers $3>4>2=1$ (Fig. $4 \mathrm{c}$ ); all toe tips with circum-marginal grooves, all tips, except that of toe 1 wider than penultimate phalanges; toes not webbed, relative lengths $4>3>5>2>1$ (Fig. $4 d$ ); plantar and palmar tubercles (with exception of small, but prominent inner metatarsal tubercle), as well as subarticular tubercles scarcely visible. Dorsal surfaces with only a few tubercles and a raised mid-dorsal ridge, ventral surfaces smooth (Fig. 4b). 

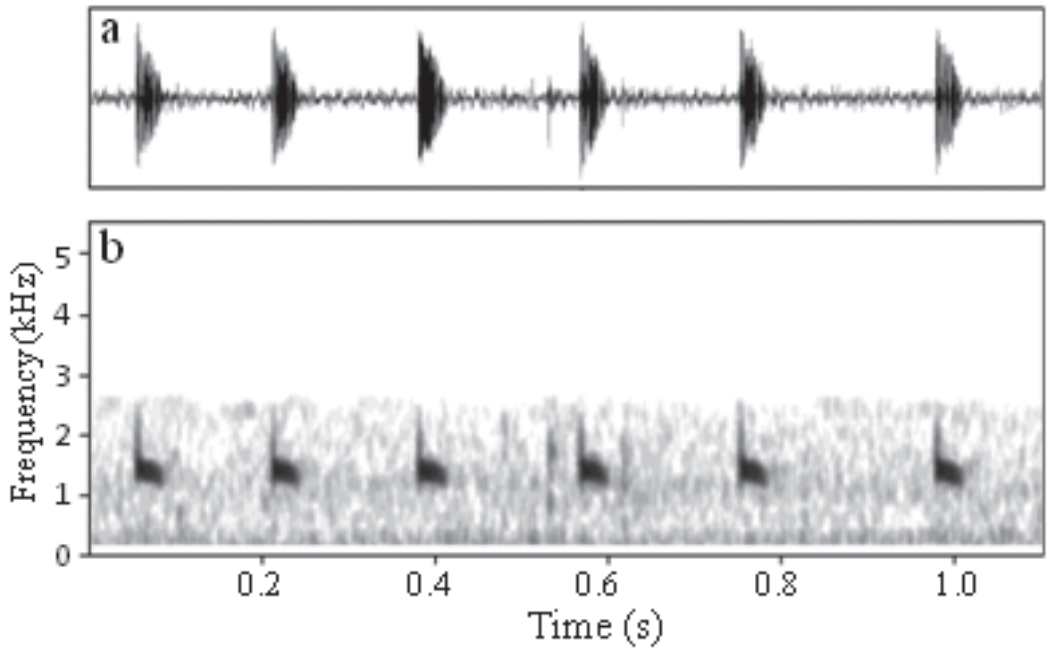

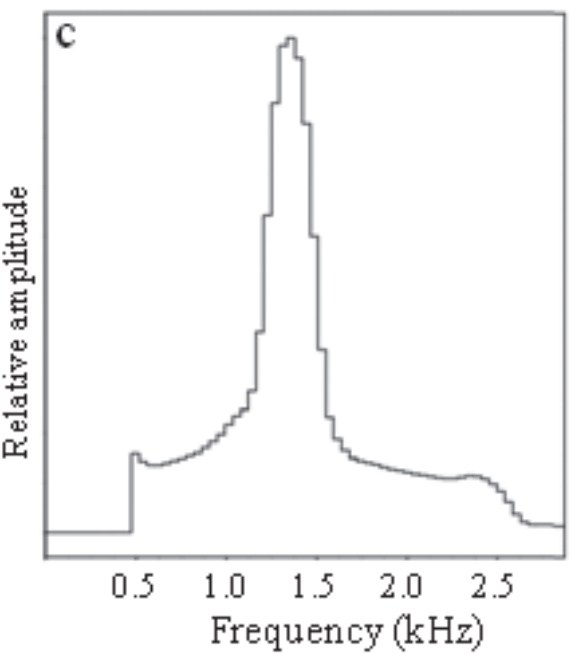

Figure 5. (a) Oscillogram and (b) Spectrogram of the last six calls of a call series containing 31 calls from the holotype of Xenorhina perexigua sp. nov.; (c) Amplitude spectrum of an advertisement call from the holotype of $X$. perexigua sp. nov.

In life, dorsal surfaces beige brown with darker areas on upper flanks, in middle of back and in scapular region (Fig. 4a); lower flanks with whitish spots and whitish reticulations and three (left side of body) or four (right side of body) irregular dark brown flecks which merge with dark brown reticulum of abdomen; supratympanic area with conspicuous dark brown fleck; all ventral surfaces light grey with dense dark brown reticulations (Fig. 4b); lumbar spot absent; vent and adjacent areas of thighs enclosed in large, triangular dark brown patch, borders of which disintegrate ventrally; outer margin of iris blackish, inner margin golden.

In preservative, dorsal surfaces reddish-brown, flanks with dark irregular spots and supratympanic region with large, dark brown fleck; ventral surfaces ivory-white with brown beige (RAL 1011) reticulum; large ivory-white area between eye and insertion of fore-leg present (not evident in life).

Distribution and ecological notes. Xenorhina perexigua sp. nov. is known only from one locality, in hill forest at an altitude of $950 \mathrm{~m}$ a.s.l. in the upper Strickland River basin of south-western Papua New Guinea (Fig. 8). The holotype was calling from within leaf litter on the forest floor at night during rain.

Vocalisation. Two call series, produced by the holotype (SAMA R71645) at an air temperature of $21.2{ }^{\circ} \mathrm{C}$, were analysed. Each call is a single soft, unpulsed "pop" note uttered in rapid succession (Fig. 5a). The two series lasted $4.1 \mathrm{~s}$ and $4.5 \mathrm{~s}$ and contained 28 and 31 calls produced at a rate of 6.8 and 6.9 calls/s. Call length 29$42 \mathrm{~ms}$ (mean $34.6 \pm 3.6 \mathrm{~ms}, \mathrm{n}=59$ ) and inter-call interval 101-195 ms (mean $115.0 \pm 17.1 \mathrm{~ms}, \mathrm{n}=57$ ). While calls are of approximately equal length throughout each series, inter-call intervals are slightly longer at the end of call series than at the beginning. Volume of calls increases during course of series, as is typical for many Xenorhina species. Calls start abruptly at high amplitude, which then decreases at an irregular rate until the end of each call (Fig. 5a). The start of each call also has a broad frequency range that drops rapidly to a more narrowly defined, frequency-modulated band (Fig. 5b). Fundamental and dominant frequency peak at $1.4 \mathrm{kHz}$ (Fig. 5c).

Etymology. The specific epithet perexigua is a Latin adjective of feminine gender, meaning very small (translation of perexiguus, -a, -um in the Dictionarium latino-germanicum means "sehr klein") and refers to the diminutive size of the new species.

Comparisons with other species. Although this species is represented by only a single specimen, it is an adult male of very small size (16.7 SUL $\mathrm{mm}$ ) and, given knowledge about the size ranges of congeners, its SUL is unlikely to exceed $25 \mathrm{~mm}$. We, therefore, compare Xenorhina perexigua sp. nov. with all congeners of a similar size (SUL 15-25 mm) that have a single spike on each vomeropalatine.

Xenorhina anorbis (Blum \& Menzies, 1989) is larger (holotype is an adult male with SVL of $21.3 \mathrm{~mm}$ [range of type series $21.3-23.4 \mathrm{~mm}$ but sex of other specimens not specified] vs. SUL $16.7 \mathrm{~mm}$ in one male), has hind legs shorter $(\mathrm{TL} / \mathrm{SVL}<0.38 \mathrm{vs} .>0.38)$ and discs of fingers and toes not wider than penultimate phalanges (vs. discs on toes 2-5 clearly wider than penultimate phalanges in Xenorhina perexigua sp. nov.).

Xenorhina brachyrhyncha Kraus, 2011 appears to be larger (two adult females with SVL 21.2 and $22.8 \mathrm{~mm}$ vs. SUL $16.7 \mathrm{~mm}$ in one male), with snout blunt in dorsal and ventral view (vs. strongly acuminate), head wider and longer (HW/ SVL $0.35-0.38$ vs. 0.32 and HL/SVL $0.30-0.32$ vs. 0.28 ) with much lower ratio of eye-naris distance to internarial distance (END/IND 1.06-1.13 in X. brachyrhyncha vs. 1.27 in Xenorhina perexigua sp. nov.); differences in colour include lack of a dark supratympanic spot in X. brachyrhyncha (vs. present in Xenorhina perexigua sp. nov.) and less pronounced dark reticulation on all ventral surfaces. 
Xenorhina lanthanites is larger SUL 21.3-22.4 mm vs. SUL $16.7 \mathrm{~mm}$ ), with tips of toes wider than penultimate phalanges only on $4^{\text {th }}$ toe (vs. toes $2-5$ with expanded terminal discs); ratio of END/IND lower (0.94-1.20 vs. 1.27); and advertisement call series much longer, lasting up to more than one minute (vs. $<5 \mathrm{~s}$ ) with average call length of $121 \mathrm{~ms}$ (vs. $35 \mathrm{~ms}$ in Xenorhina perexigua sp. nov.), dominant frequency of about $1.0 \mathrm{kHz}$ (vs. $1.4 \mathrm{kHz}$ ) and call repetition rate of 1-2 calls/s (vs. 6.8-6.9 calls/s).

Although it is known from just one specimen, it is an adult male suggesting that Xenorhina perexigua sp. nov. is amongst the smallest known members of the genus. Only one other species, $X$. bouwensi, may be smaller than Xenorhina perexigua sp. nov., but it can be immediately distinguished from the new species by its lacking odontoid spikes on the vomeropalatines.

\section{Xenorhina pohleorum sp. nov.}

http://zoobank.org/91F9054A-3CF0-4672-8A86-F64F6A2BA7AA

Holotype. SAMA R71644 (SJR 14202), adult male, from Rentoul River, Western Province, Papua New Guinea $\left(6.4355^{\circ} \mathrm{S}, 142.5615^{\circ} \mathrm{E} ; 380 \mathrm{~m}\right.$ a.s.1.), collected on 11-082014 by S.J. Richards and K. Aplin.

Paratype. SAMA R60217 (SJR 3223), adult male, Darai Plateau, Gulf Province, Papua New Guinea (7.1295 ${ }^{\circ}$ S, $143.6134^{\circ} \mathrm{E}$; $435 \mathrm{~m}$ a.s.1.), collected on 1-082003 by S.J. Richards.

Diagnosis. This species of Xenorhina is characterised by the unique combination of: small size (SUL of two adult males 20.3 and $21.2 \mathrm{~mm}$ ); vomeropalatines each with a single moderately developed triangular vomerine spike; legs of medium length (TL/SUL 0.44 in both specimens); all fingers without and all toes with, expanded terminal discs; tips of all fingers and toes with circum-marginal grooves, all grooves extending at least partly along digits; head short (HL/SUL 0.26 in both specimens); eye-naris distance greater than internarial distance (END/ IND 1.33 in both specimens); dorsal surfaces in life brown-beige (RAL 1011) or grey-brown; ventral surfaces ivory-white with extensive pale brown (RAL 8025) reticulation; mid-dorsal line and lumbar spots absent; advertisement calls uttered in series lasting 4-9 s, containing 10-30 "piping" calls, each 56-93 ms duration with repetition rate of $2.5-3.6$ calls $/ \mathrm{s}$.

Description of the holotype. Measurements are summarised in Table 3. Body squat (Fig. 6a and b), head broader than long (HL/HW 0.83); snout short (HL/SUL 0.26), strongly acuminate from above and below, protruding in profile; tongue broad, only its lateral edges and posterior lobes free; prepharyngeal ridge with few tiny denticles; vomerine spikes triangular and of moderate size; loreal region oblique, canthus rostralis absent; nostrils near
Table 3. Body measurements and body ratios of the male holotype of Xenorhina pohleorum sp. nov. (SAMA R71644) and the male paratype (SAMA R60217). All measurements in mm; for explanation of abbreviations see "Material and methods".

\begin{tabular}{|c|c|c|c|}
\hline Reg.-No. & SAMA R71644 & SAMA R60217 & Mean \\
\hline SUL & 20.3 & 21.2 & 20.75 \\
\hline $\mathrm{TL}$ & 9.0 & 9.4 & 9.20 \\
\hline TaL & 5.9 & 5.7 & 5.80 \\
\hline T4L & 9.0 & 9.7 & 9.35 \\
\hline T4D & 0.7 & 0.7 & 0.70 \\
\hline T1D & 0.4 & 0.4 & 0.40 \\
\hline F3L & 3.6 & 3.8 & 3.70 \\
\hline F3D & 0.4 & 0.4 & 0.40 \\
\hline F1D & 0.3 & 0.3 & 0.30 \\
\hline $\mathrm{HL}$ & 5.3 & 5.5 & 5.40 \\
\hline HW & 6.4 & 6.5 & 6.45 \\
\hline END & 1.6 & 1.7 & 1.65 \\
\hline IND & 1.2 & 1.3 & 1.25 \\
\hline SL & 2.6 & 3.0 & 2.80 \\
\hline EST & 2.2 & 2.5 & 2.40 \\
\hline ED & 1.3 & 1.2 & 1.25 \\
\hline TyD & 1.2 & 0.9 & 1.05 \\
\hline TL/SUL & 0.44 & 0.44 & 0.44 \\
\hline TaL/SUL & 0.29 & 0.27 & 0.28 \\
\hline T4L/SUL & 0.44 & 0.46 & 0.45 \\
\hline T4D/SUL & 0.035 & 0.033 & 0.034 \\
\hline T1D/SUL & 0.020 & 0.019 & 0.020 \\
\hline F3L/SUL & 0.178 & 0.179 & 0.179 \\
\hline F3D/SUL & 0.020 & 0.019 & 0.020 \\
\hline F1D/SUL & 0.015 & 0.017 & 0.016 \\
\hline T4D/F3D & 1.75 & 1.75 & 1.75 \\
\hline $\mathrm{T} 1 \mathrm{D} / \mathrm{F} 1 \mathrm{D}$ & 1.33 & 1.33 & 1.33 \\
\hline HL/SUL & 0.26 & 0.26 & 0.26 \\
\hline HW/SUL & 0.32 & 0.31 & 0.32 \\
\hline $\mathrm{HL} / \mathrm{HW}$ & 0.83 & 0.85 & 0.84 \\
\hline END/SUL & 0.079 & 0.080 & 0.080 \\
\hline IND/SUL & 0.059 & 0.061 & 0.060 \\
\hline END/IND & 1.33 & 1.31 & 1.32 \\
\hline ED/SUL & 0.064 & 0.057 & 0.061 \\
\hline TyD/SUL & 0.059 & 0.042 & 0.051 \\
\hline TyD/ED & 0.92 & 0.75 & 0.84 \\
\hline SL/SUL & 0.129 & 0.142 & 0.136 \\
\hline EST/SUL & 0.109 & 0.118 & 0.114 \\
\hline
\end{tabular}

tip of snout, directed more laterally than dorsally, visible from above, but not from below; eye-naris distance significantly greater than internarial distance (END/IND $1.33)$; tympanum nearly as large as eye (TyD/ED 0.92); supratympanic fold weakly expressed, not reaching eye or insertion of fore leg; shank moderately long (TL/SUL 0.44 ); fingers moderately short, not webbed, all fingers without and all toes with expanded terminal discs; circum-marginal grooves on all fingers and all toes, extending at least partly along most digits; head short (HL/SUL 0.26 ); eye-naris distance greater than internarial distance (END/IND 1.33); tympanum slightly larger than half the size of eye (TyD/ED 0.59); relative lengths of fingers 3 $>4=2=1$ (Fig. 6c); toes not webbed, relative lengths 4 $>3>5>2>1$ (Fig. 6d); plantar and palmar tubercles, as well as subarticular tubercles, not clearly demarcated, with the exception of small, but prominently raised inner metatarsal tubercle (Fig. 6d). Dorsolateral surfaces of body and dorsal surfaces of shanks with some tubercles, more conspicuous in life than in preservative; ventral surfaces smooth; tip of snout lighter than surrounding skin, with some tiny depressions. 

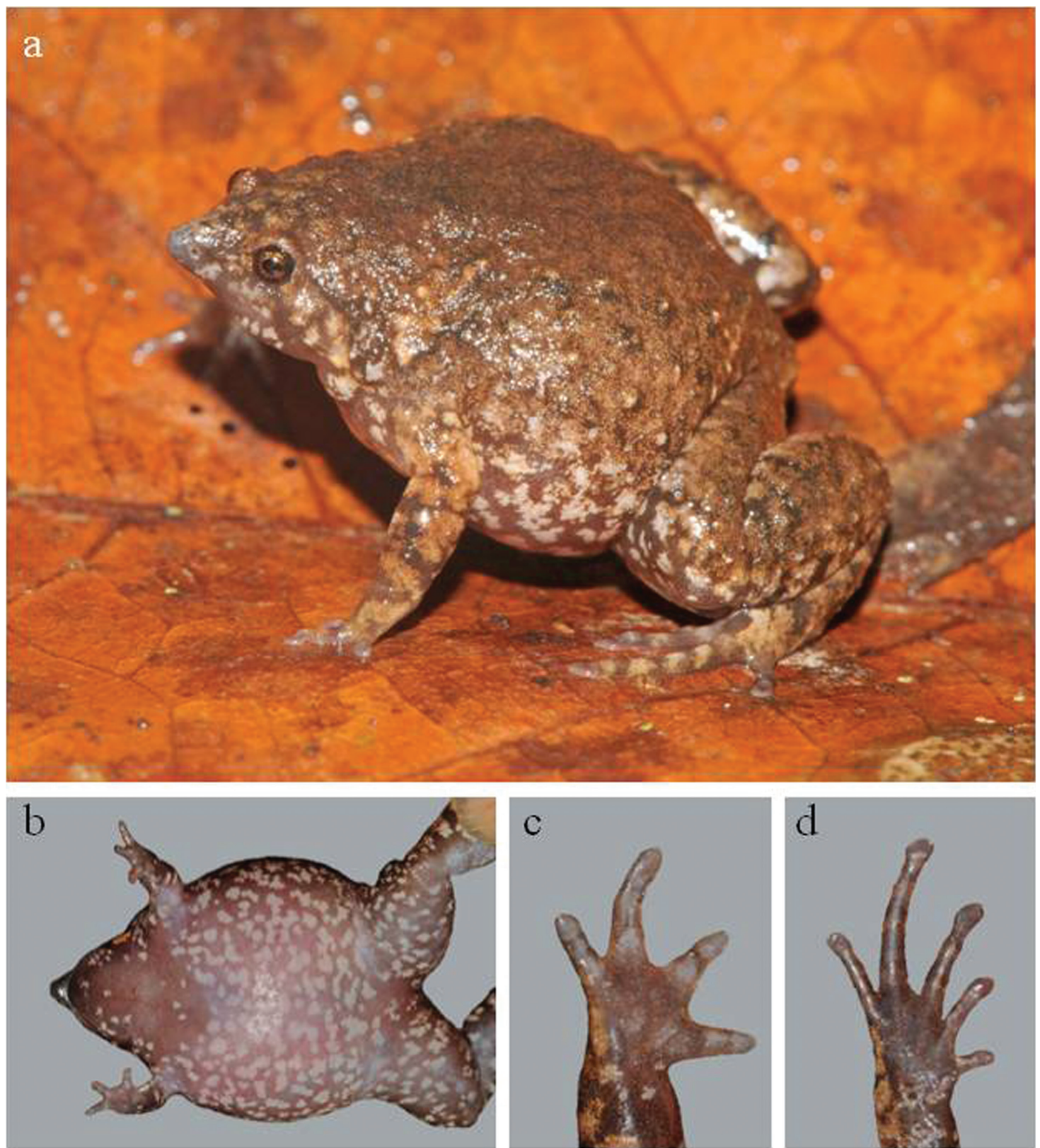

Figure 6. Holotype (SAMA R71644) of X. pohleorum sp. nov. in life: (a) Dorsolateral view; (b) Ventral view; (c) Volar view of right hand; (d) Thenar view of right foot.

In life, dorsal surfaces brown beige (RAL 1011); lumbar spots and mid-dorsal line absent; tubercles with whitish apices concentrated on upper flanks; lower flanks, lateral surfaces of head and anterior hind limbs off-white with conspicuous fawn (RAL 8007) reticulum; snout tip window grey (RAL 7040); iris blackish with few golden specks (Fig. 6a); ventral surfaces pearl-white (RAL 1013) with dusky pink (RAL 3014) reticulum and irregular pearl-white spots; throat dusky pink with only a few whitish spots (Fig. 6b).

In preservative, ground colour of dorsal surfaces of head, back and hind limbs fawn brown (RAL 8007) with some inconspicuous darker areas; head less densely pigmented than adjacent neck; ground colour of dorsal surfaces of fore limbs and anterior hind limbs beige (RAL 1001) with conspicuous terra-brown strikes and reticula; rear of thighs predominantly terra-brown with a few whitish spots below and small blackish area around vent; ventral surfaces fawn-brown with conspicuous pearl-white spots; throat and middle of chest least spotted.

Morphological variation. Measurements and body ratios of paratype are similar to holotype (Table 3). Dorsal 
surfaces more tubercular in life (Fig. 7), but in preservative, lateral surfaces with fewer tubercles; colour of dorsal surfaces in life a mixture of indistinct lighter and darker grey-brown flecks, lower lateral surfaces of body and upper arms beige-brown (RAL 8024) with off-white spots and ventral surfaces beige-brown with off-white spots. Dorsal surfaces in preservative beige with signal brown (RAL 8002) spots, stripes and reticula; ventral surfaces in preservative paler than holotype, light ivory (RAL 1015) with scarcely visible brownish network.

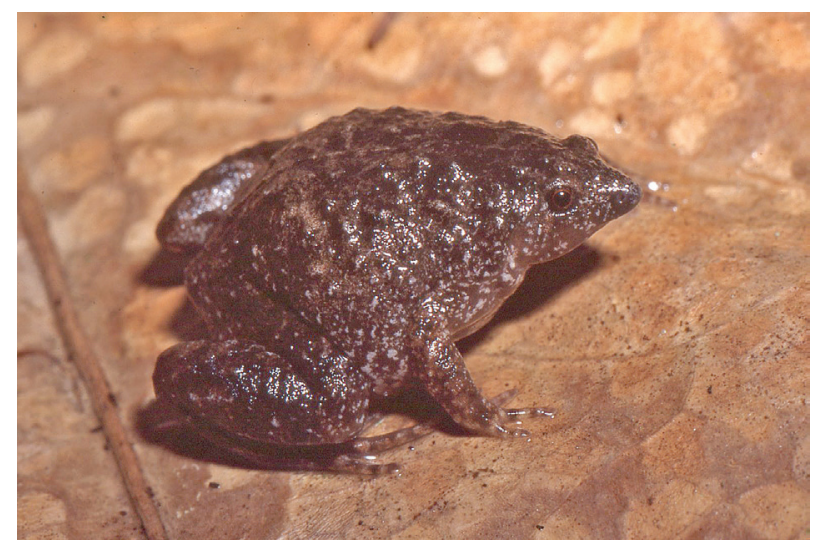

Figure 7. Paratype SAMA R60217 of X. pohleorum sp. nov. in life.
Distribution and ecological notes. Xenorhina pohleorum sp. nov. is known from two localities approximately $140 \mathrm{~km}$ apart in the lowland rainforests of Gulf and Western Provinces in south-central Papua New Guinea (Fig. 8), where males called from under the litter or within the humus layer, at night during rain.

Vocalisation. Advertisement call is a single short, unpulsed and melodic "piping" note and is always uttered in series. Call length and inter-call interval are variable, but call intervals are always much shorter than the interval between call series. Due to some differences in call features, we analysed five call series from the holotype (SAMA R71644) recorded at an air temperature of $24^{\circ} \mathrm{C}$ separately from seven call series produced by the paratype (SAMA R60217) at an air temperature of $22^{\circ} \mathrm{C}$. Call series produced by the holotype last 3.6-8.8 s (mean $5.8 \pm$ $1.8 \mathrm{~s}$ ) and contain 13-28 calls (mean $18.2 \pm 5.6$ ) produced at a rate of 2.55-3.61 calls/s (mean $3.22 \pm 0.41, \mathrm{n}=5$ ). Call length is $56-93 \mathrm{~ms}$ (mean $74.5 \pm 8.5 \mathrm{~ms}, \mathrm{n}=91$ ) and length of call intervals is 139-528 ms (mean 253.4 $\pm 71.7 \mathrm{~ms}, \mathrm{n}=86$ ). Calls start abruptly at maximum or almost maximum amplitude which then decreases at an irregular rate until end of call (Fig. 9a). Fundamental and dominant frequencies are at $1.5 \mathrm{kHz}$ and the only upper harmonic (at $3.0 \mathrm{kHz}$ ) has much less energy (Fig. 9b and

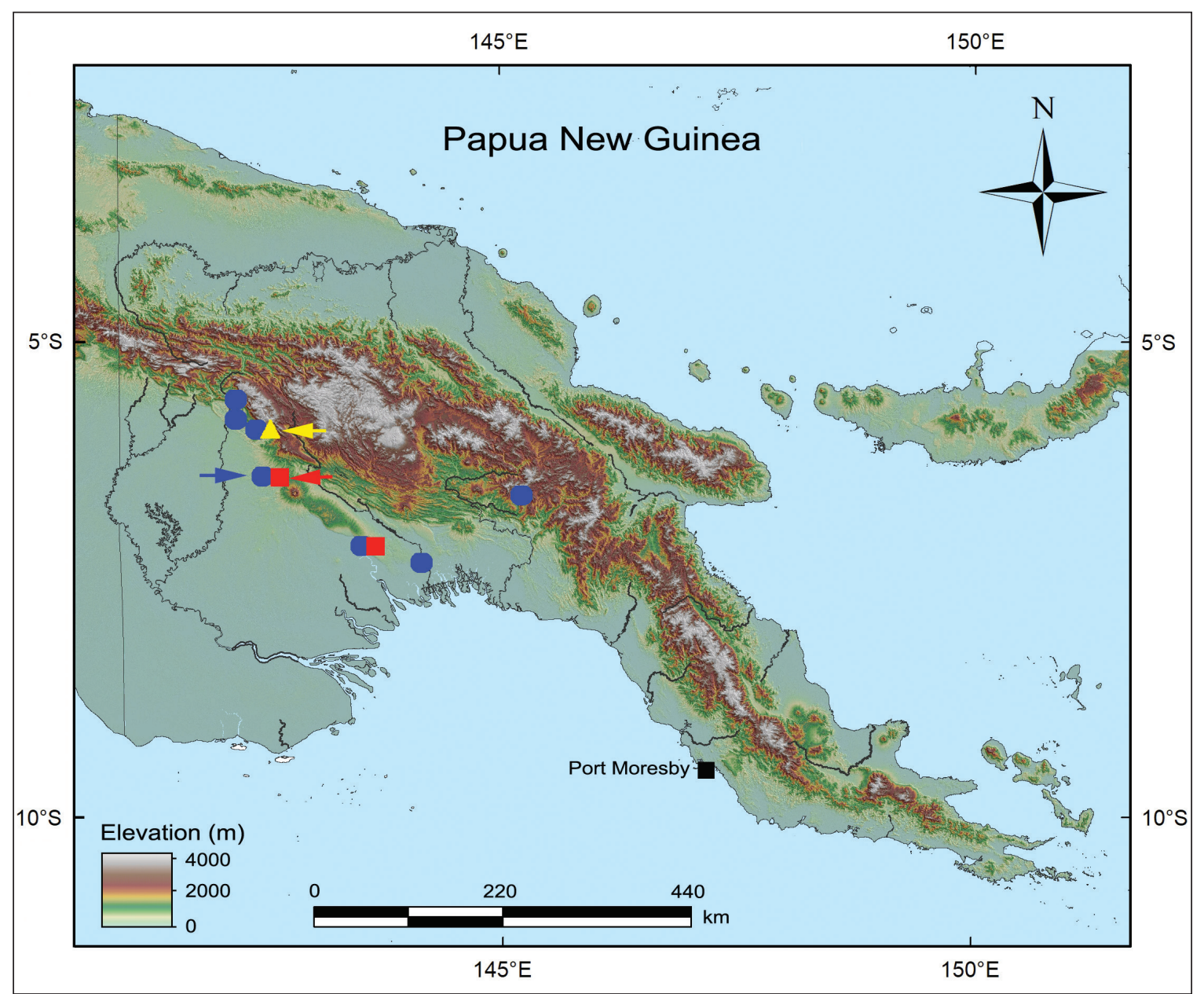

Figure 8. Map of Papua New Guinea showing the known distributions of X. lacrimosa sp. nov. (blue circles), X. perexigua sp. nov. (yellow triangle) and $X$. pohleorum sp. nov. (red squares). Arrows indicate the type localities. 

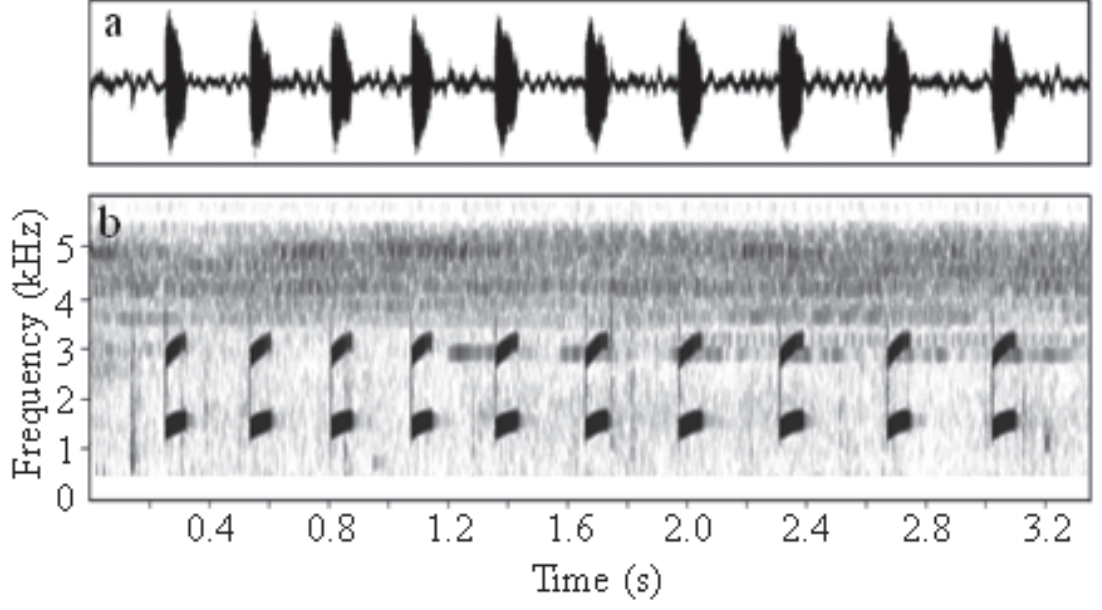

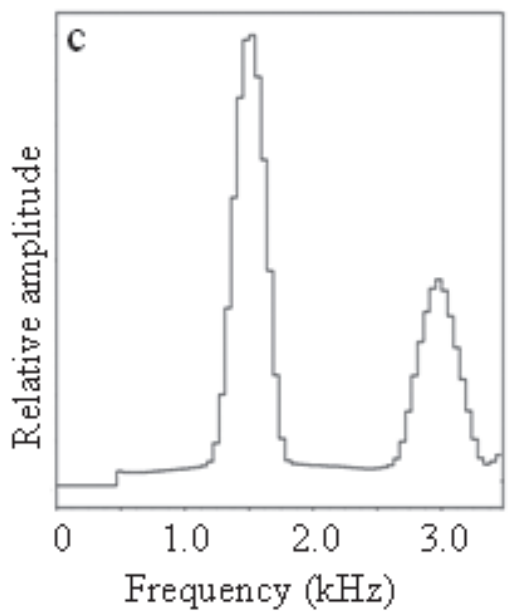

Frequency $(\mathrm{kHz})$
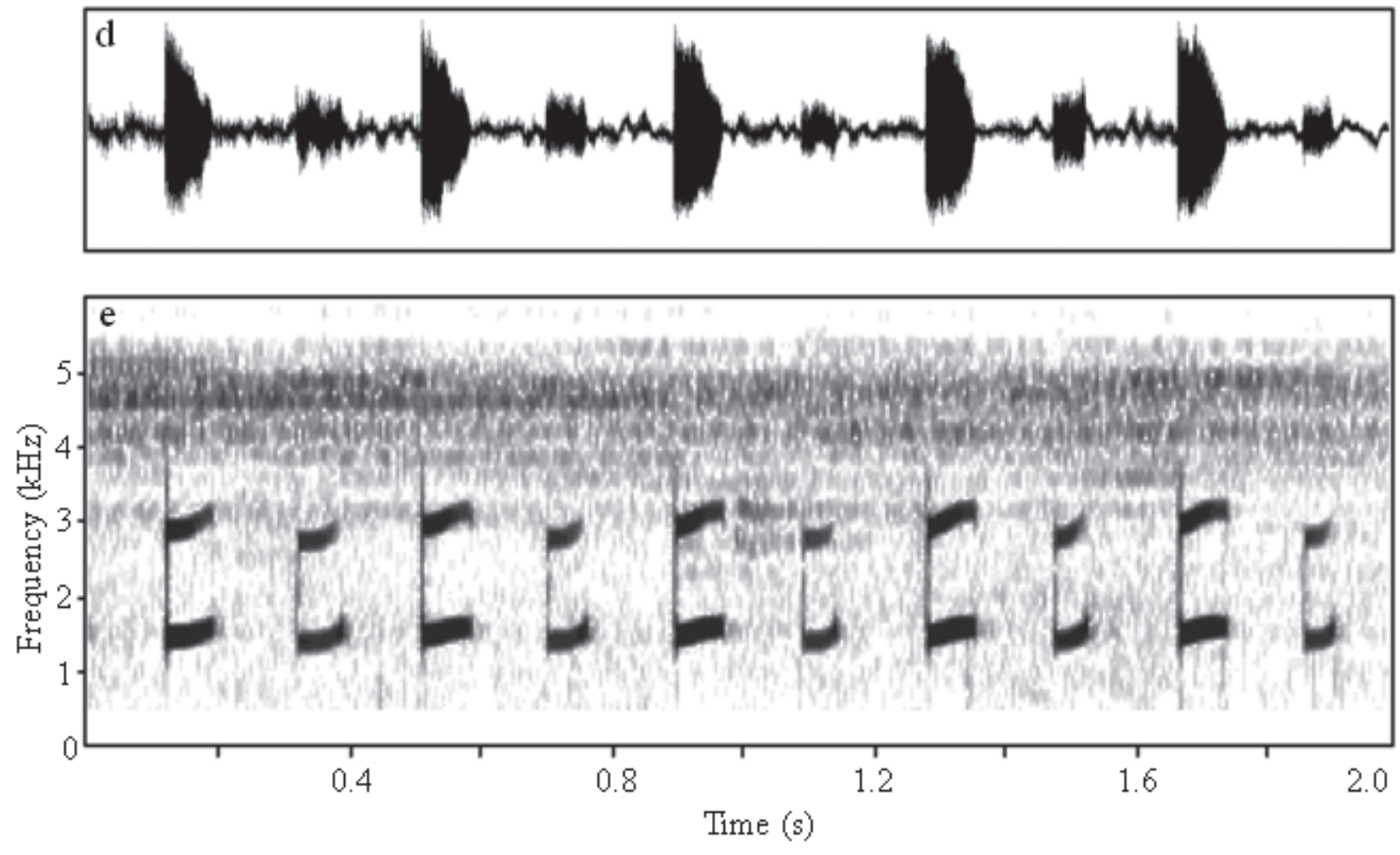

Figure 9. (a) Oscillogram; (b) Spectrogram and (c) Amplitude spectrum of 10 consecutive advertisement calls from a longer series produced by the holotype of Xenorhina pohleorum sp. nov; (d) Oscillogram and (e) Spectrogram of six advertisement calls from the holotype of $X$. pohleorum sp. nov. (higher volume) are answered in exact antiphony by an unvouchered male (lower volume).

9c). Frequency of calls is weakly modulated with a slight increase over the duration of the call. A number of calls were uttered in exact antiphony with calls from an unvouchered specimen (Fig. 9d and 9e).

Calls of the paratype (SAMA R60217) are similar to those of the holotype, but call series generally contain fewer calls $(10-15$, mean $12.9 \pm 1.77, \mathrm{n}=7$, vs. $13-28$ mean 18.2; see above) and so are shorter (3.4-5.4 s, mean $4.6 \pm 0.72 \mathrm{~s}, \mathrm{n}=7$ vs. $3.6-8.8 \mathrm{~s}$, mean $5.8 \pm 1.8 \mathrm{~s})$, although there is some overlap. Calls of the paratype are also slightly longer (66-98 ms, mean $88.4 \pm 4.8 \mathrm{~ms}, \mathrm{n}=$ 89 vs. 56-93 ms, mean 74.5). Other structural parameters of calls from the paratype fall within the range produced by the holotype: inter-call intervals 234-408 ms (mean
$290.0 \pm 31.1 \mathrm{~ms}, \mathrm{n}=83)$ and mean repetition rate 2.73 3.0 calls/s (mean $2.83 \pm 0.10$, range, $n=7$ ). Calls of the holotype do not show the typical increase in volume and pitch that is typical of the series produced by the paratype. However, the holotype was calling within a group of closely adjacent males and exhibited antiphonal calling behaviour (Fig. 9d and 9e). It cannot be discounted that the slight differences noted between calls of holotype and paratype were a result of their different calling situations (alone vs. within a chorus).

Etymology. The specific epithet pohleorum is the Latinised patronymic adjective in genitive plural derived from the family name Pohle. It is to recognise a very 
long-lasting friendship of the senior author with Sybille and Claus Pohle from Berlin.

Comparisons with other species. We compare Xenorhina pohleorum sp. nov. with all congeners of a similar size (SUL 18-25 mm) that have a single spike on each vomeropalatine.

Xenorhina anorbis has hind legs shorter (TL/SVL $<$ 0.38 vs. $>0.38)$ and fingers and toes without expanded terminal discs (vs. enlarged discs on all toes in Xenorhina pohleorum sp. nov.).

Xenorhina brachyrhyncha has legs longer (TL/SVL $0.46-0.49$ vs. twice 0.44 ), head longer (HL/SVL 0.30-0.32 vs. twice 0.26 ) and broader (HW/SVL $0.35-0.38$ vs. 0.310.32 ), with END/IND ratio lower (1.06-1.13 vs. 1.31-1.33).

Xenorhina lanthanites has expanded disc only on $4^{\text {th }}$ toe (vs. on all toes), head broader (HW/SVL 0.35-0.37 vs. $0.31-0.32$ ), eyes larger (ED/SUL 0.071-0.081 vs. $0.057-0.064)$, END/IND ratio lower (0.94-1.20 vs. $1.31-$ 1.33) and advertisement call series much longer (up to more than one minute vs. less than 10 seconds).

Xenorhina mehelyi appears to be much larger (SVL 20.7-35.2 mm vs. 20.3-21.2 mm); although the sex (or state of maturity) of previously reported specimens is unknown, with a male SUL of 20.3-21.2 mm, it is unlikely that Xenorhina pohleorum sp. nov. of either sex will approach the upper size limit reported for X. mehelyi. Xenorhina mehelyi also has eyes larger (ED/SVL 0.0670.079 vs. $0.057-0.064$ ) and different advertisement calls. Mean call interval $1.5 \mathrm{~s}$, (vs. $0.25 \mathrm{~s}$ ) and mean call rate 0.60 calls/s (vs. 3.2 calls/s); calls are also longer (mean $140 \mathrm{~ms}$ vs. $74.5 \mathrm{~ms}$ ) and have a much lower dominant frequency (0.88 kHz vs. $1.5 \mathrm{kHz}$ ) (Blum and Menzies 1989).

Xenorhina perexigua is smaller than Xenorhina pohleorum sp. nov. (males $16.7 \mathrm{~mm}$ vs. 20.3-21.2 mm SUL). Some body ratios also differ (Tables 2 and 3), but sample sizes are too small for robust comparisons. However, substantial differences in advertisement calls support recognition of Xenorhina pohleorum sp. nov. as a distinct species: calls of Xenorhina perexigua sp. nov. are shorter (29-42 ms vs. 56-93 ms), there are more calls/series (28-31 vs. 10-28 calls) and inter-call intervals are shorter (101-195 ms vs. 139-528 ms), so the call rate is twice as fast in Xenorhina perexigua sp. nov. (6.8-6.9 calls/s vs. 2.6-3.6 calls/s). The substantially greater call rate of Xenorhina perexigua sp. nov. (double that of Xenorhina pohleorum sp. nov.) cannot be attributed to differences in temperature because the recording temperature for the former was lower than that of latter, which should reduce, not increase, the call rate.

Xenorhina schiefenhoeveli (Blum \& Menzies, 1989) is larger (SVL 26.7-30.7 mm vs. 20.3-21.2 mm) and its call series lasts more than $100 \mathrm{~s}$ (vs. not more than $10 \mathrm{~s}$ in Xenorhina pohleorum sp. nov.), with call intervals of more than $700 \mathrm{~ms}$ (vs. $<528 \mathrm{~ms}$ ).

Xenorhina tumulus (Blum \& Menzies, 1989) is larger (male SVL more than $26.0 \mathrm{~mm}$ vs. less than $22.0 \mathrm{~mm}$ ), has ventral surfaces of toes with striped pattern (vs. absent) and abdomen partly pink or red (vs. pearl-white with dusky pink reticulum and irregular pearl-white spots); and supratympanic ridge is absent (vs. present). Advertisement calls of $X$. tumulus differ in, amongst other characters, having a much lower dominant frequency $(0.9 \mathrm{kHz}$ vs. $1.5 \mathrm{kHz})$. Xenorhina tumulus is known only from an elevation of about $1500 \mathrm{~m}$ a.s.l. in the Adelbert Range, an isolated mountain range near the north coast of Papua New Guinea, while Xenorhina pohleorum sp. nov. is known only from altitudes of around $400 \mathrm{~m}$ on the southern side of New Guinea's central cordillera.

\section{Xenorhina thiekeorum sp. nov.}

http://zoobank.org/772E7466-6C63-48E7-8CAE-96A1BE5F78F5

Holotype. SAMA R71651 (SJR 209047), adult male, from Ok Menga near Tabubil, Western Province, Papua New Guinea $\left(5.3205^{\circ} \mathrm{S}, 141.3049^{\circ} \mathrm{E}\right.$; $620 \mathrm{~m}$ a.s.1.), collected by S.J. Richards, M. Cunningham and A. Dennis on 14-11-1994.

Paratypes. ZMB 91131 (SJR 209051), PNGNM (SJR209052), SAMA R71652 (SJR209053), same details as for holotype.

Diagnosis. This species of Xenorhina is characterised by the unique combination of: moderately small size ( males 20.7-23.5 mm SUL); vomeropalatines each with one moderately developed triangular vomerine spike; legs moderately short (TL/SUL 0.40-0.44); all fingers and first toe without and toes 2-5 with, expanded terminal discs; tips of all fingers and toes with circum-marginal grooves that extend, at least partially, along most digits; head short (HL/SUL 0.26-0.28), eye-naris distance much greater than internarial distance (END/IND 1.361.54 ); tympanum approximately $2 / 3$ size of eye (TyD/ ED 0.63-0.69). Dorsal surfaces in life reddish-brown, covered extensively with small, white-tipped tubercles, lower flanks with larger off-white spots; back with faint yellowish mid-dorsal line. Advertisement calls uttered in series containing less than 10 short, extremely soft "piping" calls of 133-162 ms duration, produced at a rate of 2.5-3.0 calls/s.

Description of the holotype. Measurements are summarised in Table 4, a dorsolateral view in life is shown in Fig. 10a and ventral surfaces in life in Fig. 10b. Head broader than long (HL/HW 0.81); snout short (HL/SUL 0.27 , strongly acuminate from above and below, protruding in profile; tongue long, broad, only its lateral and posterior edges free; prepharyngeal ridge with eight small denticles; vomerine spikes triangular and of moderate size; loreal region oblique, no canthus rostralis; nostrils near tip of snout, directed dorsolaterally, visible from above, but not from below; eye-naris distance significantly greater than internarial distance (END/IND 1.46); borders of tympanum poorly defined in life and preservative, its diameter $2 / 3$ that of eye (TyD/ED 0.67); supratympanic 

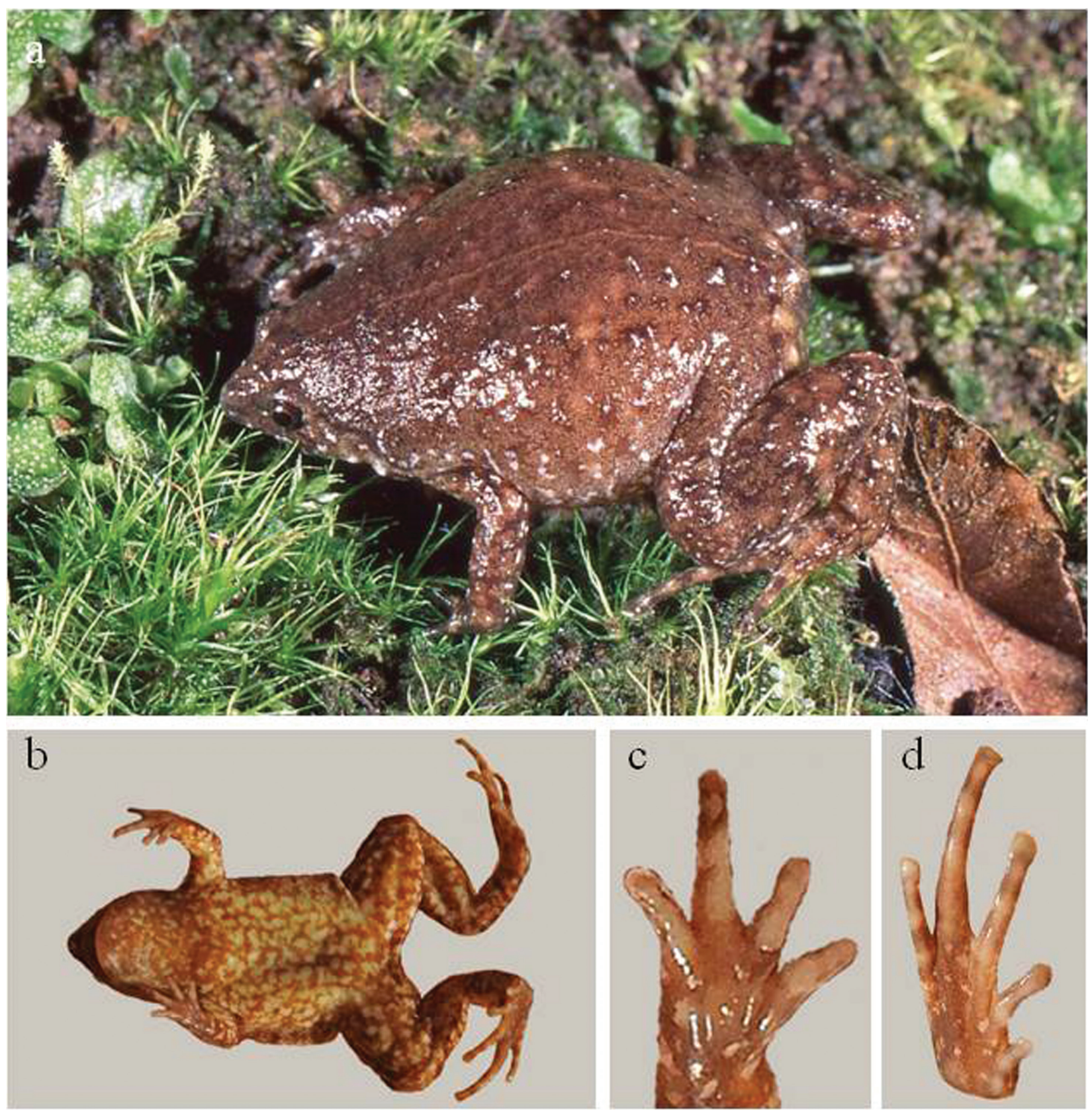

Figure 10. Holotype (SAMA R71651) of Xenorhina thiekeorum sp. nov. (a) Dorsolateral view in life; (b) Ventral view, (c) Volar view of right hand and (d) Thenar view of right foot of preserved specimen.

fold not reaching posterior edge of eye or insertion of fore-leg; shank short (TL/SUL 0.40); fingers moderately short, not webbed; all fingers and first toe without and toes 2-5 with, expanded terminal discs; circum-marginal grooves on tips of all fingers and toes, extending at least partly along most digits; relative lengths of fingers $3>4=$ $2=1$ (Fig. 10c); toes not webbed, relative lengths $4>3>$ $5>2>1$ (Fig. 10d); plantar and palmar tubercles as well as subarticular tubercles poorly defined. Dorsal surfaces with scattered low tubercles and a slightly raised yellowish mid-dorsal ridge, ventral surfaces smooth.

In life, dorsal surfaces brown beige (RAL 1011) with irregularly shaped, indistinct lighter markings in lumbar region and narrow, pale mid-dorsal line; dorsum with nu- merous small, white-tipped tubercles; lower flanks and anterior and posterior of tympana with whitish spots; dorsal surfaces of limbs and dorsal edge of tympana with few dark brown spots and/or streaks; iris blackish with scarcely visible golden veins and solid golden inner margin. Colour of ventral surfaces in life was not documented.

In preservative, ground colour of dorsal surfaces reddish-brown; dorsolateral surfaces with conspicuous blackish-brown spots, mostly associated with whitetipped tubercles; extremities and anterior back with lighter brown flecks than those on dorsolateral surfaces; solid reddish-brown areas of back merge on lower flanks into ivory-white ground colour of ventral surfaces, which are covered by a dense orange-brown reticulum. 
Morphological variation. Measurements of the type series are summarised in Table 4. Ground colour of dorsal surfaces in preservative is the same in all types (including holotype), except SAMA R71652 which is slightly paler; number and intensity of brown dorsal and lateral spots varies slightly. Ventral surfaces and rear of thighs in all frogs show a more or less dense orange brown reticulum on ivory-white ground.

Table 4. Body measurements and body ratios of the type series of Xenorhina thiekeorum sp. nov. SAMA R71651 is the male holotype. ZMB 91131, PNGNM (SJR 209052) and SAMA R71652 are male paratypes. All measurements in mm; for explanation of abbreviations see "Material and methods".

\begin{tabular}{lccccc}
\hline Reg.No. & SAMA & ZMB & PNGNM & SAMA & Mean \pm SD \\
& R71651 & 91131 & & R71652 & \\
\hline SUL & 23.0 & 20.7 & 23.5 & 22.6 & $22.45 \pm 1.22$ \\
TL & 9.2 & 9.2 & 10.1 & 9.7 & $9.55 \pm 0.44$ \\
TaL & 6.4 & 6.5 & 7.3 & 6.5 & $6.68 \pm 0.42$ \\
T4L & 9.2 & 9.7 & 10.3 & 10.1 & $9.83 \pm 0.49$ \\
T4D & 0.7 & 0.7 & 0.8 & 0.7 & $0.73 \pm 0.05$ \\
T1D & 0.4 & 0.4 & 0.5 & 0.5 & $0.45 \pm 0.06$ \\
F3L & 4.3 & 4.1 & 5.0 & 4.5 & $4.48 \pm 0.39$ \\
F3D & 0.5 & 0.5 & 0.6 & 0.6 & $0.55 \pm 0.06$ \\
F1D & 0.3 & 0.3 & 0.5 & 0.4 & $0.38 \pm 0.09$ \\
HL & 6.1 & 5.8 & 6.4 & 5.9 & $6.05 \pm 0.26$ \\
HW & 7.5 & 6.9 & 7.7 & 7.3 & $7.35 \pm 0.34$ \\
END & 1.9 & 1.7 & 2.0 & 1.9 & $1.88 \pm 0.13$ \\
IND & 1.3 & 1.2 & 1.3 & 1.4 & $1.30 \pm 0.08$ \\
SL & 2.8 & 2.5 & 2.7 & 2.6 & $2.65 \pm 0.13$ \\
EST & 2.5 & 2.4 & 2.6 & 2.3 & $2.45 \pm 0.13$ \\
ED & 1.8 & 1.6 & 1.6 & 1.7 & $1.68 \pm 0.09$ \\
TyD & 1.2 & 1.0 & 1.1 & 1.1 & $1.10 \pm 0.08$ \\
TL/SUL & 0.40 & 0.44 & 0.43 & 0.43 & $0.43 \pm 0.017$ \\
TaL/SUL & 0.28 & 0.31 & 0.31 & 0.29 & $0.30 \pm 0.015$ \\
T4L/SUL & 0.40 & 0.47 & 0.44 & 0.45 & $0.44 \pm 0.029$ \\
T4D/SUL & 0.030 & 0.034 & 0.034 & 0.031 & $0.032 \pm 0.002$ \\
T1D/SUL & 0.017 & 0.019 & 0.021 & 0.022 & $0.020 \pm 0.002$ \\
F3L/SUL & 0.187 & 0.198 & 0.212 & 0.199 & $0.199 \pm 0.010$ \\
F3D/SUL & 0.022 & 0.024 & 0.026 & 0.027 & $0.025 \pm 0.002$ \\
F1D/SUL & 0.013 & 0.014 & 0.017 & 0.018 & $0.016 \pm 0.002$ \\
T4D/F3D & 1.40 & 1.40 & 1.33 & 1.17 & $1.33 \pm 0.108$ \\
T1D/F1D & 1.33 & 1.33 & 1.00 & 1.25 & $1.23 \pm 0.156$ \\
HL/SUL & 0.27 & 0.28 & 0.27 & 0.26 & $0.27 \pm 0.008$ \\
HW/SUL & 0.33 & 0.33 & 0.33 & 0.32 & $0.33 \pm 0.005$ \\
HL/HW & 0.81 & 0.84 & 0.83 & 0.81 & $0.82 \pm 0.015$ \\
END/SUL & 0.083 & 0.082 & 0.085 & 0.084 & $0.084 \pm 0.001$ \\
IND/SUL & 0.057 & 0.058 & 0.055 & 0.062 & $0.058 \pm 0.003$ \\
END/IND & 1.46 & 1.42 & 1.54 & 1.36 & $1.45 \pm 0.075$ \\
ED/SUL & 0.078 & 0.077 & 0.068 & 0.075 & $0.075 \pm 0.005$ \\
TyD/SUL & 0.052 & 0.048 & 0.047 & 0.049 & $0.049 \pm 0.002$ \\
TyD/ED & 0.67 & 0.63 & 0.69 & 0.65 & $0.66 \pm 0.026$ \\
SL/SUL & 0.122 & 0.121 & 0.115 & 0.115 & $0.118 \pm 0.004$ \\
EST/SUL & 0.109 & 0.116 & 0.111 & 0.102 & $0.110 \pm 0.006$ \\
\hline & & & & &
\end{tabular}

Distribution and ecological notes. Xenorhina thiekeorum sp. nov. is known only from the type locality adjacent to the Ok Menga ("Ok" = River in the local Min language), at an altitude of $620 \mathrm{~m}$ a.s.l. in the foothills of the Hindenburg Range, Ok Tedi headwaters in Western Province, Papua New Guinea (Fig. 16). The frogs were calling from 1-3 cm beneath the soil surface at the base of ginger plants after rain at night. Unlike many Xenorhina species, the distribution of calling males was "clumped"; all four frogs were detected by their calls within an area of approximately $4 \mathrm{~m}^{2}$ of wet hill forest, while none was heard calling in apparently suitable adjacent forest.

Vocalisation. Three call series from the holotype (SAMA R71651) recorded at an air temperature of $22.5^{\circ} \mathrm{C}$ were analysed, but due to poor recording quality, the lengths of calls and length of call intervals could not be measured for one of these series. Calls are a single, unpulsed "piping" notes produced in short series. Calls are extremely soft and were barely audible to the human ear. Call series contain $6-8$ calls produced at a rate of 2.5-3.0 calls/s and last 2.0-2.9 s (mean $2.3 \mathrm{~s}$ ) (Fig. 11a and b). Call length is $133-162 \mathrm{~ms}$ (mean $143.4 \pm 8.8 \mathrm{~ms}, \mathrm{n}=14$ ) and length of call intervals is $168-376 \mathrm{~ms}$ (mean $250.6 \pm$ $51.8 \mathrm{~ms}, \mathrm{n}=12$ ). There are four harmonics with frequency peaks at 1.1, 2.2, 3.3 and $4.4 \mathrm{kHz}$; the third harmonic carries the dominant frequency (Fig. 11c). Volume and pitch of calls both increase marginally during the course of call series.

Etymology. The specific epithet thiekeorum is the Latinised patronymic adjective in genitive plural of the family name Thieke. It is given to recognise a very long-lasting friendship of the senior author with Heidi and Ulrich (Uli) Thieke from Berlin.

Comparisons with other species. We compare Xenorhina thiekeorum sp. nov. with all congeners of a similar size (males with SUL 18-25 mm) that have a single spike on each vomeropalatine.

Xenorhina anorbis has hind legs shorter (TL/SVL < 0.38 vs. $>0.38$ ), digital discs on toes absent (vs. expanded discs present on toes 2-5) and END/IND ratio lower (1.26-1.32 vs. 1.36-1.54).

Xenorhina brachyrhyncha has legs longer (TL/SVL $0.46-0.49$ vs. $0.40-0.44$ ), head longer (HL/SVL 0.30 0.32 vs. $0.26-0.28)$ and broader (HW/SVL $0.35-0.38$ vs. $0.32-0.33$ ) and END/IND ratio much lower (1.06-1.13 vs. 1.36-1.54).

Xenorhina lanthanites has legs longer (TL/SUL 0.44 0.46 vs. $0.40-0.44$ ), dilated disc only on $4^{\text {th }}$ toe (vs. dilated discs on toes 2-5), T4D/F3D ratio higher (1.50-2.0 vs. 1.17-1.40), END/IND ratio lower (0.94-1.20 vs. 1.361.54) and advertisement call series much longer (up to more than one minute vs. a few seconds), with call intervals longer (397-896 ms vs. 168-376 ms) and repetition rate lower (1.2-1.8 vs. $2.5-3.0$ calls/s).

Xenorhina mehelyi is probably much larger (SVL to $>35 \mathrm{~mm}$ vs. males $20.7-23.5 \mathrm{~mm}$ ), internarial distance greater (IND/SVL $0.061-0.077$ vs. $0.055-0.062$ ) and has different advertisement calls: call series of $X$. mehelyi contain $>10$ calls produced at a rate of 0.60 calls/s (vs. $<10$ calls produced at a rate of 2.75 calls/s in Xenorhina thiekeorum sp. nov.); and dominant frequency is $0.88 \mathrm{kHz}$ in $X$. mehelyi (vs. $3.3 \mathrm{kHz}$ in $X$. thiekeorum).

Xenorhina perexigua is smaller $(16.7 \mathrm{~mm}$ vs. 20.7-23.5 mm SUL) and many body ratios differ from 

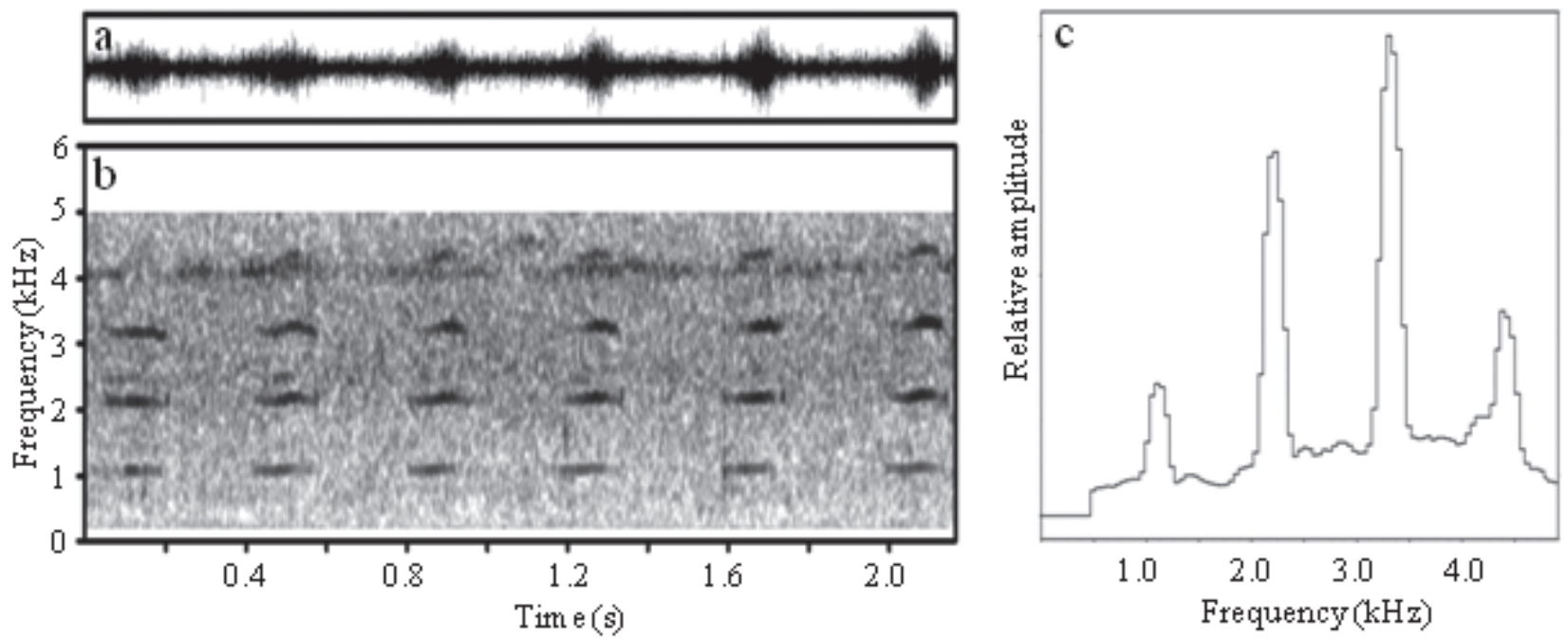

Figure 11. (a) Oscillogram; (b) Spectrogram and (c) amplitude spectrum of a series of six calls from the holotype of Xenorhina thiekeorum sp. nov.

Xenorhina thiekeorum sp. nov. (Tables 2 and 4), but small sample sizes preclude robust comparisons of body ratios. Advertisement calls differ as follows: Xenorhina perexigua sp. nov. utters calls in series lasting more than $4 \mathrm{~s}$, containing about 30 calls produced at rate of $6.8-6.9$ calls/s (vs. call series lasting $2-3 \mathrm{~s}$ containing just 6-8 calls produced at rate of $2.5-3.0$ calls/s); call length of Xenorhina perexigua sp. nov. is also much shorter (29$42 \mathrm{~ms}$ vs. 133-162 ms in Xenorhina thiekeorum sp. nov.).

Xenorhina pohleorum has fingers shorter (F3L/SUL $0.178-0.179$ vs. $0.187-0.212$ ), disc on third finger smaller (F3D/SUL $0.019-0.020$ vs. 0.022-0.027), T4D/F3D ratio higher (1.75 vs. 1.17-1.40), END/IND ratio lower (1.31-1.33 vs. $1.36-1.54)$, eyes smaller (ED/SUL $0.057-$ 0.064 vs. $0.068-0.078)$ and TyD/ED ratio higher $(0.75-$ 0.92 vs. $0.63-0.69)$. Moreover, call length of Xenorhina pohleorum sp. nov. is much shorter ( 70-90 ms vs. 130-150 ms).

Xenorhina schiefenhoeveli is larger (SVL 26.7$30.7 \mathrm{~mm}$ vs. $20.7-23.5 \mathrm{~mm}$ ), with ratio of END/IND lower (1.04-1.33 vs. 1.36-1.54) and different calls; call series last $>100 \mathrm{~s}$ (vs. 2-3 s in Xenorhina thiekeorum sp. nov.), with call intervals $>700 \mathrm{~ms}$ (vs. less than $400 \mathrm{~ms}$ ).

Xenorhina tumulus is larger (SVL $>26.0 \mathrm{~mm}$ vs. $<$ $24.0 \mathrm{~mm}$ ), with internarial distance relatively longer (IND/ SVL $0.063-0.069$ vs. $0.055-0.062$ ), distance between eye and naris relatively shorter (END/SVL $0.073-0.081$ vs. $0.082-0.085)$, END/IND ratio lower (1.11-1.28 vs. 1.36$1.54)$ and call length shorter (60-70 ms vs. $133-162 \mathrm{~ms})$.

\section{Xenorhina wiegankorum sp. nov.}

http://zoobank.org/DD757B96-EAFD-427B-9844-1BD80D13544C

Holotype. SAMA R71653 (SJR 10372), adult male, from Baia River, Western Province, Papua New Guinea $\left(6.0205^{\circ} \mathrm{S}, 142.5473^{\circ} \mathrm{E} ; 330 \mathrm{~m}\right.$ a.s.1.), collected by S.J. Richards on 15-02-2008.
Paratypes. PNGNM (FN SJR10373), adult male, same details as for holotype; SAMA R71654 (FN SJR10400), adult male, from Camp 2, upper Strickland River basin, Western Province, Papua New Guinea $\left(5.9018^{\circ} \mathrm{S}\right.$, $142.4360^{\circ} \mathrm{E} ; 950 \mathrm{~m}$ a.s.1.), collected by S.J. Richards on 19-02-2008; ZMB 91132 (FN SJR14220), adult male, Rentoul River, Western Province, Papua New Guinea $\left(6.4355^{\circ} \mathrm{S}, 142.5615^{\circ} \mathrm{E} ; 380 \mathrm{~m}\right.$ a.s.1.), collected on $14-08-$ 2014 by S.J. Richards; SAMA R65073 (FN SJR10948), adult male, Gugusu Camp, Muller Range, Western Province $\left(5.7290^{\circ} \mathrm{S}, 142.2630^{\circ} \mathrm{E} ; 515 \mathrm{~m}\right.$ a.s.1.), collected by S.J. Richards and C. Dahl on 8-09-2009.

Diagnosis. This species of Xenorhina is characterised by the unique combination of: medium size (males 32.0-35.7 mm SUL); vomeropalatines each with one strongly developed triangular spike; legs moderately long (TL/SUL 0.44-0.47); all fingers tips without and all toe tips with expanded discs; eye-naris distance greater than internarial distance (END/IND 1.19-1.37); tympanum same size as, or slightly smaller than, eye (TyD/ED 0.80 1.00). Dorsal surfaces in life different shades of grey or brown; ventral surfaces different shades of red or yellow, throat and chest with some darker flecks. Advertisement calls uttered in series lasting 10-20 s and containing 2040 calls; length of calls $60-100 \mathrm{~ms}$, dominant frequency at $0.5 \mathrm{kHz}$.

Description of the holotype. Measurements are summarised in Table 5, a dorsolateral view in life is shown in Fig. 12a and ventral surfaces in life in Fig. 12b. Head broader than long (HL/HW 0.84); snout acuminate from above and below and distinctly protruding in profile; vomerine spikes strongly developed; prepharyngeal ridge clearly expressed with about 14 denticles; tongue long, broad, not bilobed posteriorly; loreal region oblique, no canthus rostralis; nostrils near tip of snout, positioned dorsolaterally, visible from above, but not from below; 

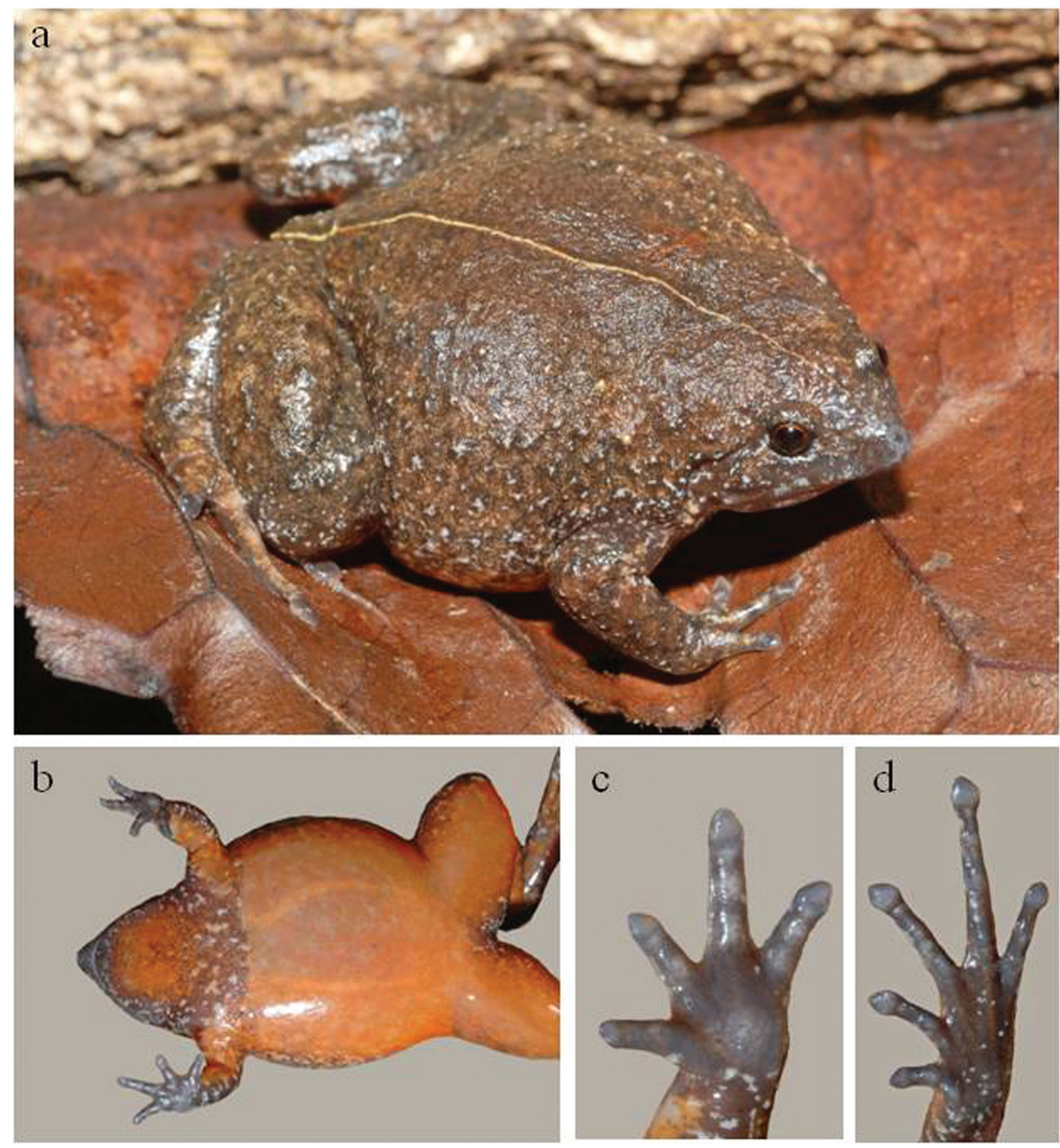

Figure 12. Holotype (SAMA R71653) of Xenorhina wiegankorum sp. nov. in life: (a) Dorsolateral view; (b) Ventral view; (c) Volar view of left hand; (d) Thenar view of left foot.

eye-naris distance greater than internarial distance (END/ IND 1.37); tympanic annulus more strongly defined in preservative than in life, its diameter smaller than that of eye (TyD/ED 0.80); well defined supratympanic fold extends from marginally behind eye to insertion of fore leg; shank moderately short (TL/SUL 0.44); fingers moderately short, not webbed, tips of all fingers not wider than penultimate phalanges, but with circum-marginal grooves, relative lengths of fingers $3>4>2=1$ (Fig. 12c); all toe tips acuminate, but wider than penultimate phalanges, with circum-marginal grooves; toes not webbed, relative lengths $4>3>5>2>1$ (Fig. 12d); plantar, palmar and subarticular tubercles barely defined. Body laterally and dorsum of legs partly, with scattered small tubercles in life and in preservative; all ventral surfaces smooth; tip of snout (especially ventrally) with several tiny elevations.

In life, all dorsal surfaces almost uniformly light olive-brown (RAL 8008); lumbar spot absent; back with yellowish mid-dorsal line that continues along hind legs on to tarsus; tubercles with whitish apices concentrated mainly on lateral surfaces of body; large dark triangular spot on posterior of thighs around vent absent; iris blackish with golden speckles; ventral surfaces of toes predominantly signal-grey (RAL 7004), plantar surfaces 
Table 5. Body measurements and body ratios of the type series of Xenorhina wiegankorum sp. nov. SAMA R71653 is the male holotype; all others are male paratypes. All measurements in mm; for explanation of abbreviations see "Material and methods".

\begin{tabular}{|c|c|c|c|c|c|c|}
\hline Reg.-No. & $\begin{array}{c}\text { SAMA } \\
\text { R71653 }\end{array}$ & $\begin{array}{c}\text { PNGNM } \\
\text { (SJR10373) }\end{array}$ & $\begin{array}{c}\text { ZMB } \\
91132\end{array}$ & $\begin{array}{c}\text { SAMA } \\
\text { R71654 }\end{array}$ & $\begin{array}{c}\text { SAMA } \\
\text { R65073 }\end{array}$ & Mean \pm SD \\
\hline SUL & 32.4 & 32.0 & 34.9 & 33.1 & 35.7 & $33.62 \pm 1.61$ \\
\hline TL & 14.4 & 14.9 & 16.0 & 15.5 & 15.6 & $15.38 \pm 0.63$ \\
\hline TaL & 9.5 & 10.0 & 10.7 & 10.4 & 10.2 & $10.16 \pm 0.45$ \\
\hline T4L & 14.5 & 15.1 & 16.3 & 15.6 & 16.8 & $15.66 \pm 0.92$ \\
\hline T4D & 1.2 & 1.3 & 1.2 & 1.3 & 1.4 & $1.28 \pm 0.08$ \\
\hline T1D & 0.9 & 0.9 & 0.8 & 1.0 & 0.9 & $0.90 \pm 0.07$ \\
\hline F3L & 6.1 & 6.8 & 6.7 & 7.0 & 7.1 & $6.74 \pm 0.39$ \\
\hline F3D & 0.8 & 0.9 & 0.7 & 0.8 & 0.8 & $0.76 \pm 0.09$ \\
\hline F1D & 0.7 & 0.8 & 0.7 & 0.7 & 0.7 & $0.72 \pm 0.05$ \\
\hline $\mathrm{HL}$ & 9.0 & 9.5 & 8.6 & 9.1 & 9.7 & $9.18 \pm 0.43$ \\
\hline HW & 10.7 & 11.3 & 11.9 & 11.5 & 11.4 & $11.36 \pm 0.43$ \\
\hline END & 2.6 & 2.7 & 2.7 & 2.5 & 2.5 & $2.60 \pm 0.10$ \\
\hline IND & 1.9 & 2.1 & 2.2 & 2.1 & 2.0 & $2.06 \pm 0.11$ \\
\hline$S L$ & 4.1 & 4.2 & 4.5 & 4.7 & 4.5 & $4.40 \pm 0.24$ \\
\hline EST & 3.9 & 3.8 & 3.9 & 4.0 & 4.1 & $3.94 \pm 0.11$ \\
\hline ED & 2.0 & 2.1 & 2.2 & 2.2 & 2.2 & $2.14 \pm 0.09$ \\
\hline TyD & 1.6 & 2.0 & 1.9 & 2.1 & 2.2 & $1.96 \pm 0.23$ \\
\hline TL/SUL & 0.44 & 0.47 & 0.46 & 0.47 & 0.44 & $0.46 \pm 0.015$ \\
\hline TaL/SUL & 0.29 & 0.31 & 0.31 & 0.31 & 0.29 & $0.30 \pm 0.011$ \\
\hline T4L/SUL & 0.45 & 0.47 & 0.47 & 0.47 & 0.47 & $0.47 \pm 0.009$ \\
\hline T4D/SUL & 0.037 & 0.041 & 0.034 & 0.039 & 0.039 & $0.038 \pm 0.003$ \\
\hline T1D/SUL & 0.028 & 0.028 & 0.023 & 0.030 & 0.025 & $0.027 \pm 0.003$ \\
\hline F3L/SUL & 0.188 & 0.213 & 0.192 & 0.211 & 0.199 & $0.201 \pm 0.011$ \\
\hline F3D/SUL & 0.025 & 0.028 & 0.020 & 0.024 & 0.022 & $0.024 \pm 0.003$ \\
\hline F1D/SUL & 0.022 & 0.025 & 0.020 & 0.021 & 0.020 & $0.022 \pm 0.002$ \\
\hline T4D/F3D & 1.50 & 1.44 & 1.71 & 1.63 & 1.75 & $1.61 \pm 0.133$ \\
\hline T1D/F1D & 1.29 & 1.13 & 1.14 & 1.43 & 1.29 & $1.26 \pm 0.124$ \\
\hline HL/SUL & 0.28 & 0.30 & 0.25 & 0.27 & 0.27 & $0.27 \pm 0.018$ \\
\hline HW/SUL & 0.33 & 0.35 & 0.34 & 0.35 & 0.32 & $0.34 \pm 0.013$ \\
\hline $\mathrm{HL} / \mathrm{HW}$ & 0.84 & 0.84 & 0.72 & 0.79 & 0.85 & $0.81 \pm 0.054$ \\
\hline END/SUL & 0.080 & 0.084 & 0.077 & 0.076 & 0.070 & $0.078 \pm 0.005$ \\
\hline IND/SUL & 0.059 & 0.066 & 0.063 & 0.069 & 0.056 & $0.063 \pm 0.005$ \\
\hline END/IND & 1.37 & 1.24 & 1.23 & 1.19 & 1.25 & $1.26 \pm 0.068$ \\
\hline ED/SUL & 0.062 & 0.066 & 0.063 & 0.066 & 0.062 & $0.064 \pm 0.002$ \\
\hline TyD/SUL & 0.049 & 0.063 & 0.054 & 0.063 & 0.062 & $0.058 \pm 0.006$ \\
\hline TyD/ED & 0.80 & 0.95 & 0.86 & 0.95 & 1.00 & $0.91 \pm 0.080$ \\
\hline SL/SUL & 0.127 & 0.131 & 0.129 & 0.142 & 0.126 & $0.131 \pm 0.006$ \\
\hline EST/SUL & 0.120 & 0.119 & 0.112 & 0.121 & 0.115 & $0.117 \pm 0.004$ \\
\hline
\end{tabular}

brown-grey; ventral surfaces of fingers and palms predominantly signal-grey; abdomen and ventral surfaces of thighs, shanks and arms melon-yellow (similar to RAL 1028) with inconspicuous whitish spots; ground colour of throat and chest also melon-yellow, but overlain with dense pattern of beige-grey and off-white spots.

In preservative, all dorsal surfaces pastel-violet (RAL 4009), with only few darker areas and inconspicuous whitish tubercle apices. Melon-yellow ventral surfaces faded to ivory colour in preservative and pattern on chest and throat changed from beige-grey to brown-beige (RAL 1011).

Morphological variation. Morphometric data for all paratypes are similar (Table 5). Colour pattern of ZMB 91132 (and probably of PNGNM [SJR 10373]) in life is similar to holotype. Dorsal surfaces of SAMA R71654 are telegrey (RAL 7045) with small whitish spots (Fig. 13) and ventral surfaces predominantly broom-yellow (RAL 1032). Dorsal surfaces of SAMA R65073 are a mixture of stone-grey (RAL 7030) and brown-grey (RAL 7013)

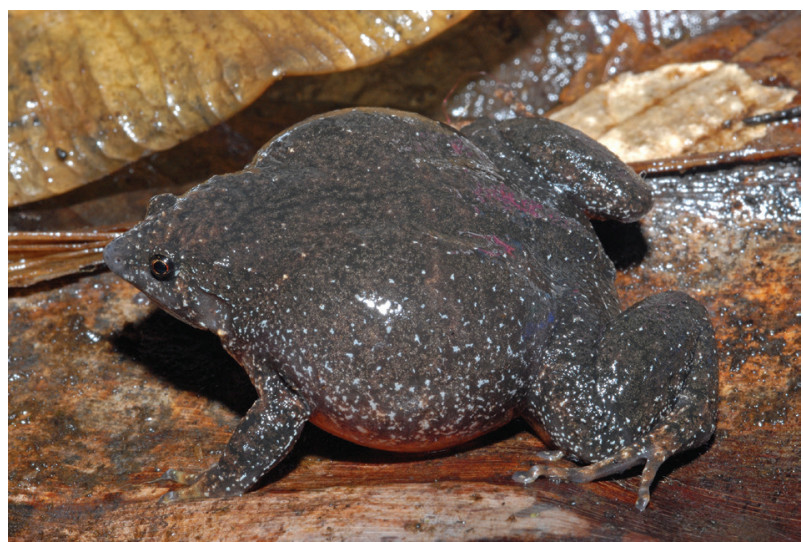

Figure 13. Xenorhina wiegankorum sp. nov. paratype SAMA R71654 in dorsolateral view.

reticula interspersed with whitish spots (mainly on lower flanks) and ventral surfaces predominantly zinc-yellow (RAL 1018).

In preservative, ground colour of dorsal surfaces of head and back of all specimens is dark shades of pastel-violet (RAL 4009), with dorsal surfaces of extremities light brown with dark brown stripes and spots. Two paratypes with and two without, light mid-dorsal line. Snout tip grey in all specimens. Part of chest, entire abdomen and ventral surfaces of thighs light ivory; throat and part of chest light ivory overlain by more or less expanded brown-beige areas. Rear of thighs in all type specimens predominantly brown, only a small area around vent blackish.

Distribution and ecological notes. Xenorhina wiegankorum sp. nov. has a known distribution limited to altitudes of 330-950 $\mathrm{m}$ a.s.l. in the foothills of the upper Strickland River catchment in Western Province, south-western Papua New Guinea (Fig. 16). Males called at night from under the litter on the forest floor or from slightly beneath the soil surface, during or immediately after heavy rain.

Vocalisation. We analysed one call series from the holotype (SAMA R71653) recorded at an air temperature of $23.7^{\circ} \mathrm{C}$, two call series from paratype SJR 10400 recorded at $21.0^{\circ} \mathrm{C}$ and one call series of paratype ZMB 91132 recorded at $25.0^{\circ} \mathrm{C}$. Calls are rather deep, unpulsed "popping" notes that, as is typical for many Xenorhina species, increase in volume during the course of the call series. Pitch of calls also increases slightly during the course of each series. Although there is some variation in call length and inter-call interval amongst calls of the three animals recorded, there is high overlap in all call parameters and we have no doubt that all represent the same species. We, therefore, combined the calls for analysis

Calls are of approximately equal length, but inter-call intervals are somewhat variable. A call starts abruptly at high amplitude, which then decreases gradually until end of call (Fig. 14a). There are 2-7 harmonics, though the second is often missing (Fig. 14b and c); fundamental and dominant frequencies are at $0.55 \mathrm{kHz}$ (Fig. 14c). Length 

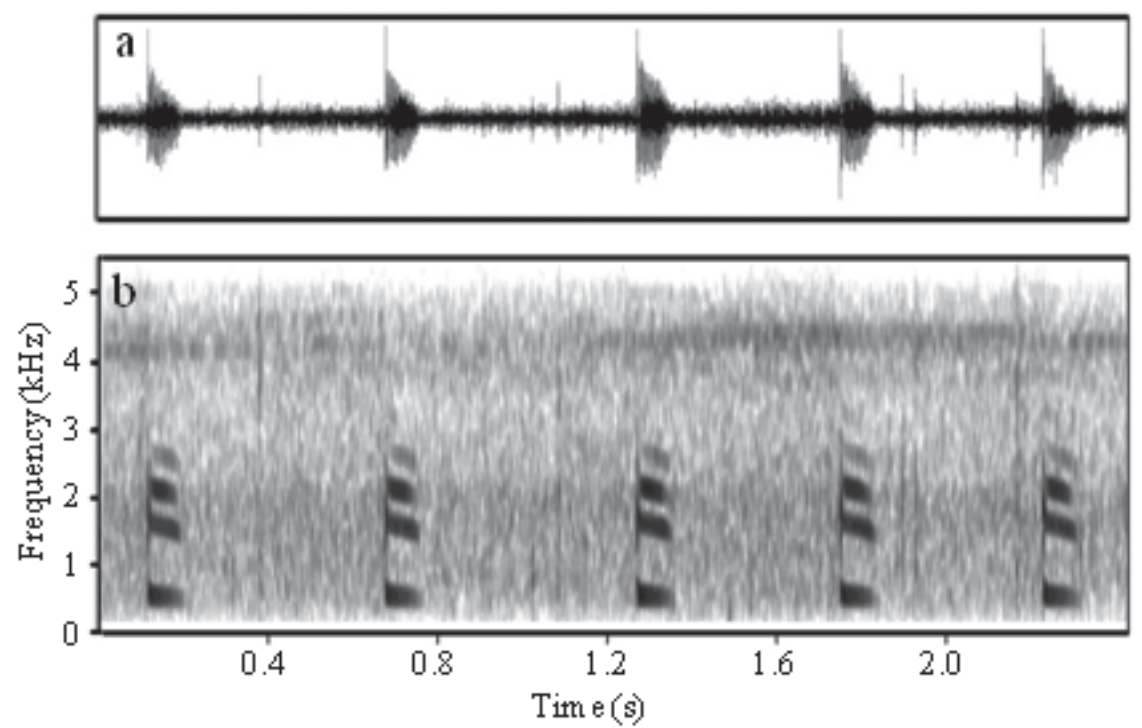

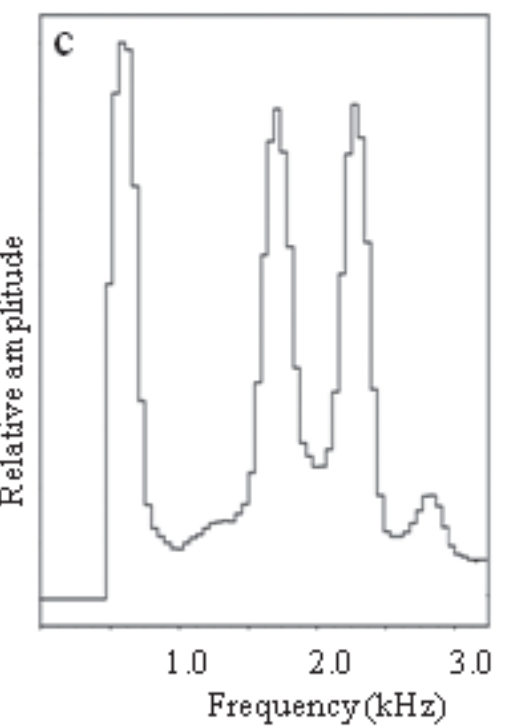

Figure 14. (a) Oscillogram; (b) Spectrogram and (c) Amplitude spectrum of the last five calls from a call series containing 29 calls, produced by paratype ZMB 91132 of Xenorhina wiegankorum sp. nov.

of call series is $13.8-18.1 \mathrm{~s}$ (mean $15.3 \mathrm{~s}, \mathrm{n}=4$ ); with 22-39 calls per series (mean 28.8, $\mathrm{n}=4$ ); call length is 60-104 ms (mean $87.1 \pm 6.7 \mathrm{~ms}, \mathrm{n}=115)$; intercall interval length is $286-1073 \mathrm{~ms}$ (mean $459.6 \pm 137.6 \mathrm{~ms}, \mathrm{n}=$ 111) with call repetition rate of $1.71-2.15$ calls/s (mean 1.86 calls/s).

Etymology. The specific epithet wiegankorum is the Latinised patronymic adjective in genitive plural of the family name Wiegank. It is given to recognise a very long-lasting friendship of the senior author with Ulla and Friedrich-Manfred (Conny) Wiegank from Potsdam.

Comparisons with other species. We compare Xenorhina wiegankorum sp. nov. with all congeners of a similar size (SUL 28-38 mm) that have a single spike on each vomeropalatine bone.

Xenorhina fuscigula has hind legs shorter (TL/SVL $<$ 0.40 vs. $>0.40$ ), eye-naris distance shorter (END/SVL 0.064-0.074 vs. 0.070-0.084) and fourth toe shorter (T4L/SVL $0.34-0.41$ vs. 0.45-0.47); advertisement calls of $X$. fuscigula are produced singly (vs. in a long series containing up to 39 calls).

Xenorhina huon (Blum \& Menzies, 1989) has hind legs shorter $(\mathrm{TL} / \mathrm{SVL}<0.40$ vs. $>0.40)$, eyes larger $(\mathrm{ED} / \mathrm{SVL}$ $0.070-0.091$ vs. $0.062-0.066)$ and ventral surfaces with dark flecking (vs. ventral surfaces without dark flecking). Xenorhina huon is also known only from mountainous regions 1800-2000 m a.s.l. on the Huon Peninsula, near the north coast of Papua New Guinea (vs. lowlands south of the central cordillera).

Xenorhina lacrimosa exhibits considerable overlap in many morphometric characters, but displays extensive variation in dorsal colouration (vs. predominantly brown or grey); vent enclosed in dark brown patch (vs. patch absent) and ventral surfaces deep orange or occasionally grey-brown, with white spots (vs. ventral surfaces at least partially yellow) (Figs 1-2 vs. 12-13); dorsal surfaces also appear less rugose in life (Figs 1-2 vs. 12-13). Advertisement calls are very different: call series of $X$. lacrimosa much longer (26-60 s vs. 12-18 s), with fewer calls (7-12 vs. $22-39)$, repetition rate much slower (0.20 0.27 vs. $1.70-2.15$ calls/s), call length longer (141-231 $\mathrm{ms}$ vs. 60 to $104 \mathrm{~ms})$ and call interval longer $(2.8-8.0 \mathrm{~s}$ vs. $286-1073 \mathrm{~ms}$ ).

Xenorhina subcrocea (Menzies \& Tyler, 1977) is smaller (SVL 30.5-33.3 vs. 32.0-35.7), with hind legs longer $(\mathrm{TL} / \mathrm{SVL}>0.46$ vs. $<0.47)$, ventral surfaces with dark reticulation in preservative (vs. without dark reticulation), call intervals within series shorter (154-285 ms vs. $286-1073 \mathrm{~ms}$ ), produced at rate of about 4 calls/s (vs. 1.7-2.2 calls/s).

Xenorhina zweifeli has similar body size and ratios. It differs from Xenorhina wiegankorum sp. nov. by having a conspicuous dark brown supratympanic stripe (vs. absent) and greatly different advertisement calls: $X$. zweifeli utters single calls at long and irregular intervals (Kraus and Allison 2002), with 2-3 calls sometimes uttered in quick succession, during the day and early evening (Kraus and Allison 2002); in contrast, Xenorhina wiegankorum sp. nov. produces calls in discrete series with 22-39 calls produced in rapid succession, only at night.

\section{Xenorhina woxvoldi sp. nov.}

http://zoobank.org/2F2CA28A-5E2F-485C-911B-E3FD35AF7E27

Holotype. SAMA R71646 (SJR10249), adult male, from southern edge of Karius Range, Hela Province, Papua New Guinea $\left(5.9911^{\circ} \mathrm{S}, 142.6707^{\circ} \mathrm{E}\right.$; 1,368 m a.s.1.), collected on 07-02-2008 by S.J. Richards.

Paratype. ZMB 91133 (SJR 10311), adult male, same collection details as for holotype. 

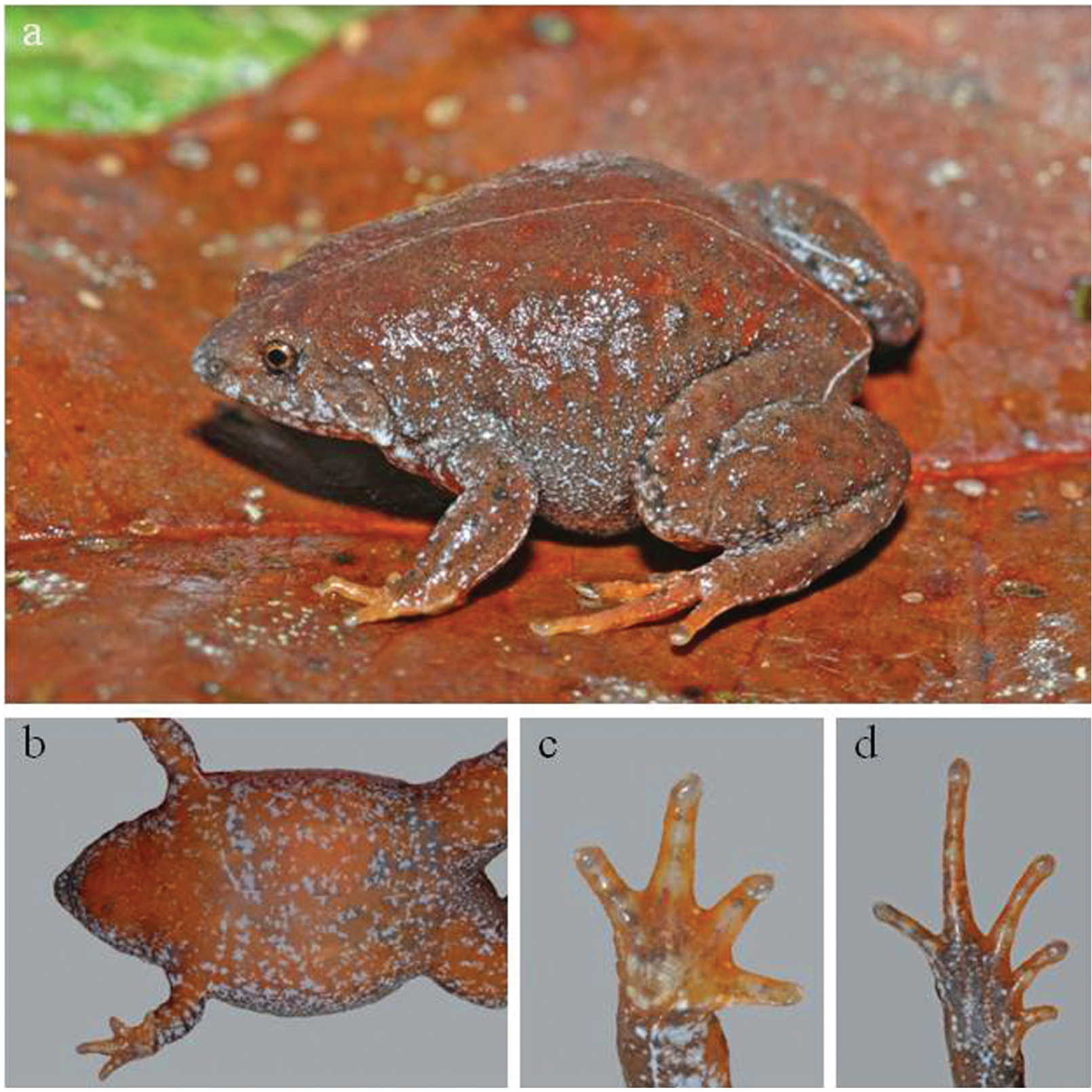

Figure 15. Holotype (SAMA R71646) of X. woxvoldi sp. nov. in life: (a) Dorsolateral view; (b) Ventral view; (c) Volar view of right hand; (d) Thenar view of right foot.

Diagnosis. This species of Xenorhina is characterised by the unique combination of: small to medium-size (males 28.7-30.1 mm SUL); vomeropalatines each with one moderate-sized vomerine spike; legs short (TL/SUL 0.36 in two specimens); all fingers and toe 1 without expanded discs, toes $2-5$ with weakly expanded discs (T4D/ SUL 0.038-0.040); eye-naris distance smaller than internarial distance (END/IND 0.80-0.91); tympanum slightly larger than eye (TyD/ED 1.11 in two specimens). Dorsal surfaces bluish-brown in life, ventral surfaces dark orange with irregular whitish and greyish spots. Advertisement calls uttered in series lasting 3-5 s, calls per series 13-19, call length $37-84 \mathrm{~ms}$, repetition rate $4.0-4.5$ calls/s.

Description of the holotype. Measurements are summarised in Table 6, a dorsolateral view in life is shown in Fig. 15a and ventral surfaces in life in Fig. 15b. Head broader than long (HL/HW 0.75); snout acuminate from above, protruding in profile; loreal region oblique, no canthus rostralis; nostrils near tip of snout, directed more laterally than dorsally, visible from above, but not from below; eye-naris distance less than internarial distance (END/IND 0.90); tympanum visible in life and preservative, its diameter slightly larger than eye (TyD/ ED 1.11); tongue very broad; vomerine spikes triangular, moderately large; prepharyngeal ridge narrow with four denticles; supratympanic fold well-developed, not reaching eye or insertion of fore leg (Fig. 15a); shank short (TL/SUL 0.36); fingers moderately short, not webbed; tips of all fingers with circum-marginal grooves, not or only marginally wider than penultimate phalanges, relative lengths of fingers $3>4>2>1$ (Fig. 15c); all toe tips 
Table 6. Body measurements and body ratios of the type series of Xenorhina woxvoldi sp. nov. SAMA R71646 is the male holotype; ZMB 91133 is a male paratype. All measurements in mm; for explanation of abbreviations see "Material and methods".

\begin{tabular}{|c|c|c|c|}
\hline Reg.-No. & SAMA R71646 & ZMB 91133 & Mean \\
\hline SUL & 30.1 & 28.7 & 29.40 \\
\hline $\mathrm{TL}$ & 10.8 & 10.4 & 10.60 \\
\hline TaL & 7.8 & 7.0 & 7.40 \\
\hline T4L & 12.2 & 12.0 & 12.10 \\
\hline T4D & 1.2 & 1.1 & 1.15 \\
\hline T1D & 0.7 & 0.6 & 0.65 \\
\hline F3L & 5.7 & 5.0 & 5.35 \\
\hline F3D & 0.8 & 0.7 & 0.75 \\
\hline F1D & 0.6 & 0.6 & 0.60 \\
\hline $\mathrm{HL}$ & 7.6 & 7.1 & 7.35 \\
\hline HW & 10.2 & 8.7 & 9.45 \\
\hline END & 1.8 & 1.6 & 1.70 \\
\hline IND & 2.0 & 2.0 & 2.00 \\
\hline SL & 3.3 & 3.1 & 3.20 \\
\hline EST & 3.0 & 2.8 & 2.90 \\
\hline ED & 1.8 & 1.9 & 1.85 \\
\hline TyD & 2.0 & 2.1 & 2.05 \\
\hline TL/SUL & 0.36 & 0.36 & 0.36 \\
\hline TaL/SUL & 0.26 & 0.24 & 0.25 \\
\hline T4L/SUL & 0.41 & 0.42 & 0.415 \\
\hline T4D/SUL & 0.040 & 0.038 & 0.39 \\
\hline T1D/SUL & 0.023 & 0.021 & 0.22 \\
\hline F3L/SUL & 0.189 & 0.174 & 0.182 \\
\hline F3D/SUL & 0.027 & 0.024 & 0.026 \\
\hline F1D/SUL & 0.020 & 0.021 & 0.021 \\
\hline T4D/F3D & 1.50 & 1.57 & 1.54 \\
\hline $\mathrm{T} 1 \mathrm{D} / \mathrm{F} 1 \mathrm{D}$ & 1.16 & 1.00 & 1.08 \\
\hline HL/SUL & 0.25 & 0.25 & 0.25 \\
\hline HW/SUL & 0.34 & 0.30 & 0.32 \\
\hline $\mathrm{HL} / \mathrm{HW}$ & 0.75 & 0.82 & 0.79 \\
\hline END/SUL & 0.060 & 0.056 & 0.058 \\
\hline IND/SUL & 0.066 & 0.070 & 0.068 \\
\hline END/IND & 0.90 & 0.80 & 0.85 \\
\hline ED/SUL & 0.060 & 0.066 & 0.063 \\
\hline TyD/SUL & 0.066 & 0.073 & 0.070 \\
\hline TyD/ED & 1.11 & 1.11 & 1.11 \\
\hline SL/SUL & 0.110 & 0.108 & 0.109 \\
\hline EST/SUL & 0.100 & 0.098 & 0.099 \\
\hline
\end{tabular}

with circum-marginal grooves, those on toes $2-4$ clearly wider than penultimate phalanges, those on toe 1 and toe 5 scarcely wider than penultimate phalanges; toes not webbed, relative lengths $4>3>5>2>1$ (Fig. 15d); plantar, palmar and subarticular tubercles barely visible; body laterally with some distinct tubercles in life, barely visible in preservative; dorsal surfaces of extremities, middle of dorsum and all ventral surfaces smooth; tip of snout with several tiny pimples.

In life, dorsal surface of head, body and extremities a mixture of grey-brown and copper-brown (RAL 8004) (Fig. 15a); lower flanks uniform greyish with bluish hue and off-white dots and streaks; semicircular lumbar spot present, but only vaguely defined; a distinct whitish mid-dorsal line extends on to rear of thighs and on shanks and tarsi, then as broken line on to abdomen and chest; dorsal and ventral surfaces of fingers and toes and palmar surfaces orange; plantar surfaces a mixture of irregular light grey, dark grey and orange spots. Ventral surfaces of throat, chest, abdomen and extremities orange-brown (RAL 8023) with irregular light grey spots (Fig. 15b); most tubercles on flanks and extremities with whitish tips; snout tip light grey with tiny dark grey spots; outer margin of iris blackish and inner margin gold-orange, with some integration of colours at their margins.

In preservative, dorsal surfaces changed from copper-brown to mahogany-brown (RAL 8016), that of ventral surfaces from orange-brown to ivory (RAL 1014). Dorsal surfaces of fingers and toes also become ivory coloured. Lumbar spots no longer visible.

Morphological variation. All body measurements and body ratios of holotype and paratype are similar (Table 6). In life, dorsal surfaces of paratype a mixture of lighter and darker brown and reddish areas, with reddish components more restricted than in holotype. Colours of flanks and dorsal surfaces of fingers and toes and colour and extent of mid-dorsal line (extending on to hind limbs and abdomen) as for holotype. Ventral surfaces more yellow and light grey spotting more extensive, in paratype. Dorsal surfaces in preservative slightly paler than holotype, ventral surface with more extensive pale brown reticulation.

Distribution and ecological notes. Xenorhina woxvoldi sp. nov. is known only from one location at an altitude of 1,368 $\mathrm{m}$ a.s.l. on the southern fringe of the Karius Range in Hela Province, Papua New Guinea (Fig. 16), where males called from within the humus layer in lower montane rainforest during late afternoon and early evening.

Vocalisation. Two call series from the holotype (SAMA R71646) and one from the paratype (ZMB 91133), recorded at air temperatures of $18-19.5^{\circ} \mathrm{C}$, were analysed. Call is a single unpulsed, piping note produced in discrete series. Call series last $2.9-4.8 \mathrm{~s}$ (mean $3.7 \mathrm{~s}, \mathrm{n}=3$ ) and contain 13-19 calls (mean 5.7 calls, $\mathrm{n}=3$ ) produced at a rate of $4.0-4.5$ calls $/ \mathrm{s}$ (mean 4.3 calls $/ \mathrm{s}, \mathrm{n}=3$ ). Call length is $37-84 \mathrm{~ms}$ (mean $75.1 \pm 8.3 \mathrm{~ms}, \mathrm{n}=47$ ) and call intervals last $137-250 \mathrm{~ms}$ (mean $172.4 \pm 28.4 \mathrm{~ms}, \mathrm{n}=44$ ). Calls are of approximately equal length throughout a series (first call may be shorter) with approximately equal intervals (intervals between first two and last two calls of a series may be slightly longer). Volume of each call increases during course of call series, but rise in pitch is marginal. Calls start abruptly at maximum amplitude, which then decreases gradually until end of call (Fig. 17a). All calls have harmonic structure with 4-5 harmonics between 0.7 and $3.2 \mathrm{kHz}$ (Fig. 17b). First harmonic clearly dominant, with peak at $0.8 \mathrm{kHz}$ (Fig. 17c). Third harmonic often with more energy than second. Frequency of calls weakly modulated with slight reduction during course of call.

Etymology. The specific epithet woxvoldi is the Latinised patronymic adjective in genitive singular derived from the family name Woxvold. It is in gratitude of the junior author to Iain Woxvold for the many years of friendship, camaraderie and shared adventures in remotest New Guinea. 


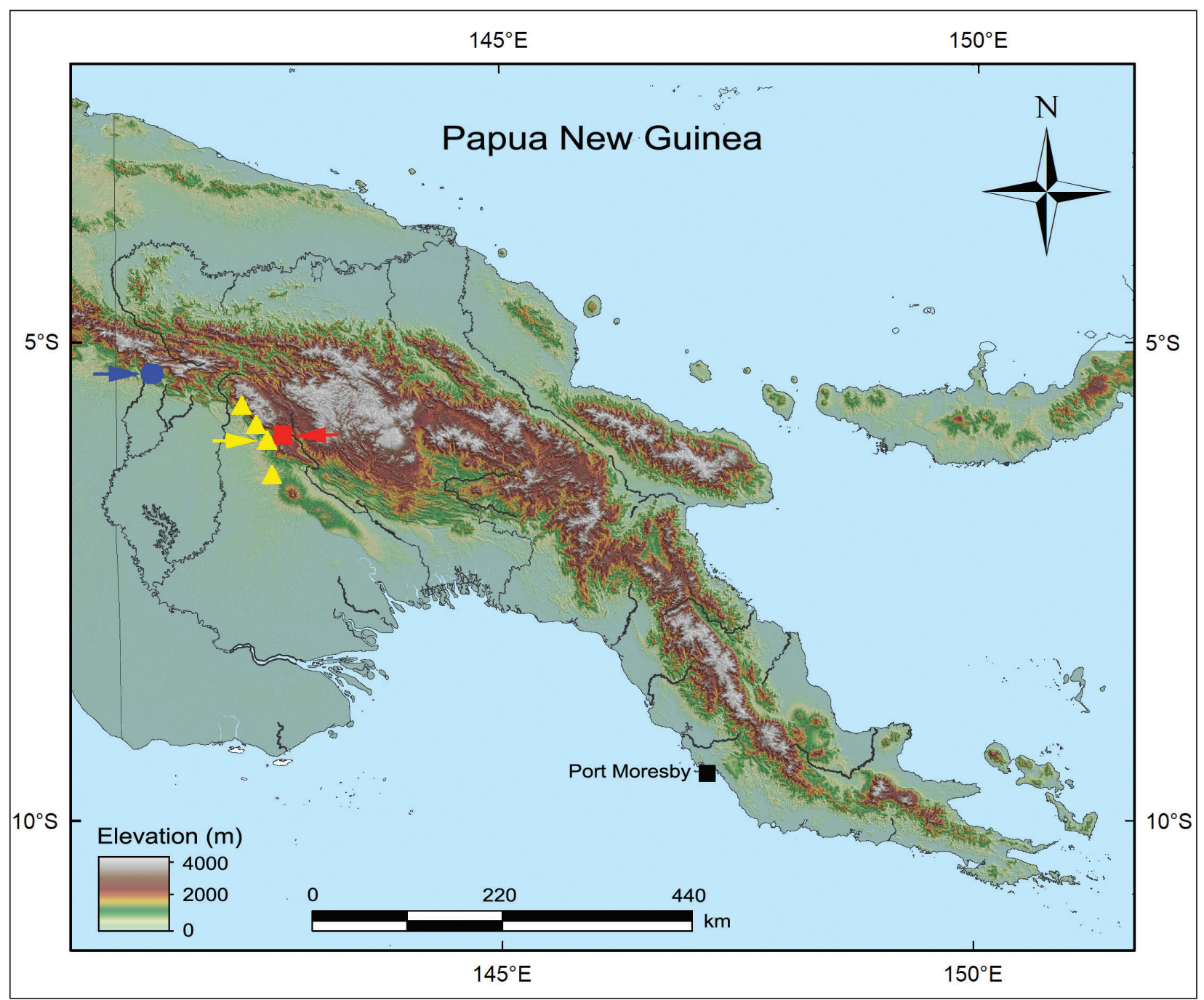

Figure 16. Map of Papua New Guinea showing the known distributions of $X$. thiekeorum sp. nov. (blue circle), $X$. wiegankorum sp. nov. (yellow triangles) and $X$. woxvoldi sp. nov. (red square). Arrows indicate the type localities.
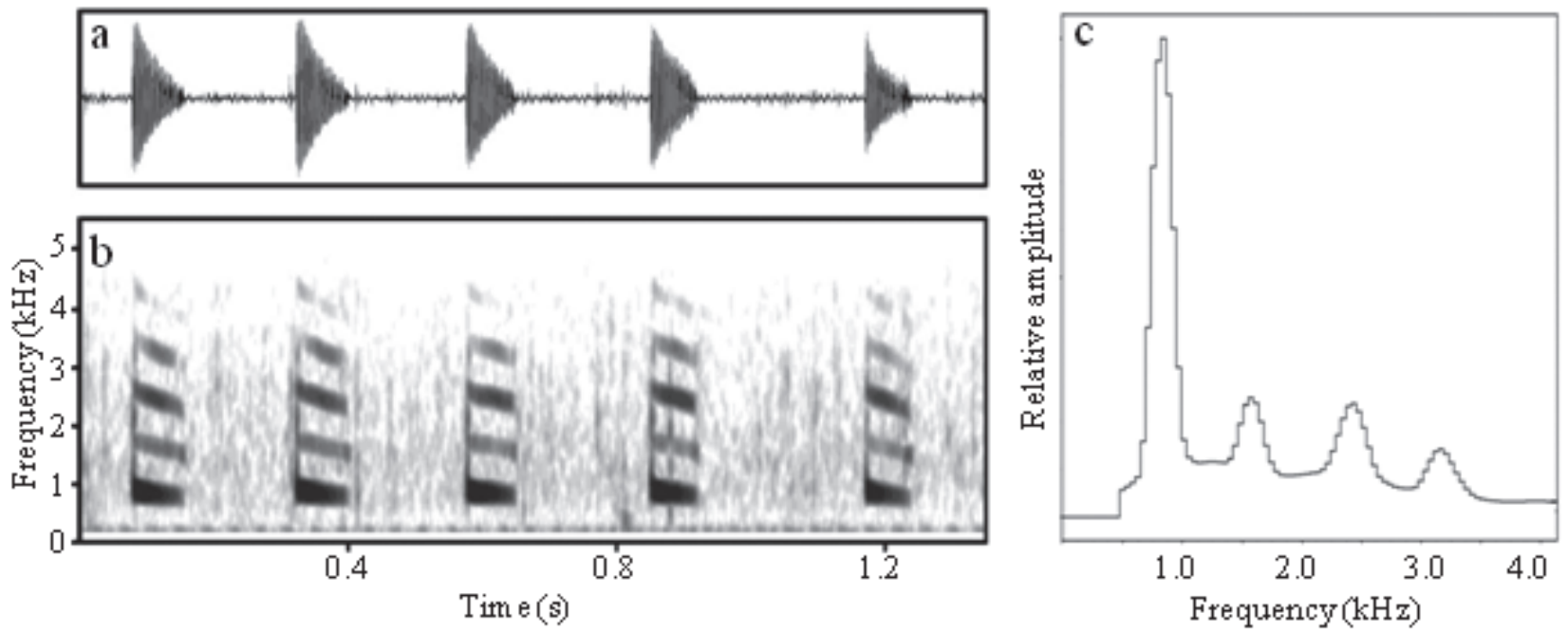

Figure 17. (a) Oscillogram, (b) Spectrogram and (c) Amplitude spectrum of the last five calls of a series containing 15 calls from the holotype of Xenorhina woxvoldi sp. nov.

Comparisons with other species. We compare Xenorhina woxvoldi sp. nov. with all congeners of a similar size (SUL $\sim 25-35 \mathrm{~mm}$ ) that have a single spike on each vomeropalatine.
Xenorhina fuscigula differs from Xenorhina woxvoldi sp. nov. by having an internarial distance shorter (IND/ SVL $0.054-0.064$ vs. 0.066-0.070), eye-naris distance greater (END/SVL $0.064-0.074$ vs. $0.056-0.060)$, END/ 
IND ratio higher (1.00-1.36 vs. 0.80-0.90), ventral surfaces pale with dark reticulation (vs. orange with light grey spots) and calls produced singly (vs. produced in rapid series of 13-19 calls).

Xenorhina huon has eye-naris distance greater $(0.073-$ 0.103 vs. $0.056-0.060)$, END/IND ratio higher (1.001.27 vs. $0.80-0.90)$, eyes larger (ED/SVL $0.070-0.091$ vs. $0.060-0.066$ ), head wider (HW/SVL $0.35-0.47$ vs. $0.30-0.34$ ) and ventral surfaces with dark flecking (vs. ventral surfaces with light flecking in life and pale brown reticulation in preservative).

Xenorhina lacrimosa is larger (SUL 34.3-41.0 mm vs. 28.7-30.1 mm), has shanks longer (TL/SUL 0.42-0.46 vs. 0.36 in both known Xenorhina woxvoldi sp. nov.), fourth toe longer (T4L/SUL $0.42-0.49$ vs. 0.41-0.42), head longer (HL/SUL $0.27-0.30$ vs. 0.25 in both known Xenorhina woxvoldi sp. nov.), eye-naris distance greater (END/SUL 0.073-0.099 vs. 0.056-0.060) and advertisement calls longer (141-231 ms vs. 37-84 ms) with lower repetition rate $(0.20-0.27$ vs. $4.0-4.5$ calls/s).

Xenorhina mehelyi has hind legs longer (TL/SVL $>0.42$ vs. 0.36), eye-naris distance greater (END/SVL 0.076-0.096 vs. 0.056-0.060), END/IND ratio higher (1.12-1.50 vs. $0.80-0.90)$, eyes larger (ED/SVL 0.0670.079 vs. $0.060-0.066$ ), ventral surfaces with dark mottling (vs. no dark mottling) and calls longer (on average $140 \mathrm{~ms}$ vs. $75 \mathrm{~ms}$ ) with inter-call intervals also longer (on average $1500 \mathrm{~ms}$ vs. $172 \mathrm{~ms}$ ).

Xenorhina schiefenhoeveli has eye-naris distance greater (END/SVL 0.077 vs. 0.056-0.060), END/IND ratio higher (1.16-1.21 vs. $0.80-0.90)$, eyes larger (ED/ SVL 0.071-0.081 vs. 0.060-0.066), ventrum cream, with reticulated brown (vs. orange-red with whitish flecking); calls longer ( $\sim 100 \mathrm{~ms}$ vs. mean of $75 \mathrm{~ms})$, uttered in very long series of more than 100 calls (vs. 13-19 calls) with repetition rate about 2 calls/s (vs. 4.0-4.5 calls/s).

Xenorhina subcrocea has hind legs longer (TL/SVL > 0.46 vs. $<0.40)$, ratio of END/IND much larger (1.261.41 vs. $0.80-0.90)$, ventral surfaces with dark reticulation (vs. with whitish flecking) and mid-dorsal line absent (vs. distinct dorsal line present).

Xenorhina tumulus has eye-naris distance greater $(0.073-$ 0.081 vs. $0.056-0.060)$, END/IND ratio higher (1.11-1.28 vs. $0.80-0.90)$, ventral surfaces in life pinkish, mottled with brown (vs. orange-brown with no brown mottling) and call intervals within series 300-400 ms (vs. 137-250 ms).

Xenorhina wiegankorum appears to be larger (five males 32.0-35.7 mm vs. two males 28.7-30.1 mm SUL), has hind legs much longer (TL/SUL $0.44-0.47$ vs. 0.36 in two specimens), has toes longer (T4L/SUL 0.45-0.47 vs. 0.41-0.42), fingers longer (F3L/SUL 0.188-0.213 vs. 0.174-0.189), END/IND ratio higher (1.19-1.37 vs. $0.80-0.90$ ) and a different advertisement call (see description of $X$. wiegankorum, this paper).

Xenorhina zweifeli is larger (SVL 33.2-38.0 vs. 28.730.1 ), with internarial distance smaller (IND/SVL 0.0520.063 vs. $0.066-0.070$ ), eye-naris distance larger (END/ SVL 0.071-0.085 vs.0.056-0.060), END/IND ratio higher (1.17-1.47 vs. $0.80-0.90)$; ventral colour pattern of dark brown flecks on a cream ground in preservative (vs. pale brown flecks on ivory-coloured ground) and call consisting of a single note (vs. 13-19 calls produced in distinct series.

\section{Discussion}

Recent assessments of anuran faunas on the large tropical islands of Sri Lanka (Meegaskumbura et al. 2002, Pethiyagoda et al. (2014) and Madagascar (Vieites et al. 2009) have revealed vastly underestimated levels of diversity. A similar pattern is emerging for New Guinea, the world's largest and highest tropical island. New Guinea has the most diverse insular anuran fauna globally, with more than 400 species currently recognised (Frost 2021). Furthermore, field-based species inventories across the Island during the past 2-3 decades have rapidly increased the rate of species discovery and description, a trend that shows no sign of approaching an asymptote (Allison 2014). This rapid advance in taxonomic knowledge of the amphibian fauna has been generated substantially by studies of morphological and bioacoustic variation (e.g. Günther 2001, Richards and Günther 2018, Kraus 2019), while molecular assessments of New Guinea anuran diversity remain relatively rare (Oliver et al. 2013).

Anuran advertisement calls are useful for taxonomic studies because they are mate recognition signals that are generally species-specific, exhibit limited variation amongst individuals and populations (although some features can be influenced in partially predictable ways by environmental factors, such as temperature) and likely have a genetic basis (Hoskin 2005, Köhler et al. 2017, Emmrich et al. 2020). We, therefore, consider the unique bioacoustics traits of each new species described here to be a strong indicator of species level divergence. Known calls of Xenorhina species reflect the acoustic constraints imposed by a fossorial existence. They comprise short, precise and melodious "hooting" or "piping" notes with a low fundamental frequency and well-defined harmonics that are normally produced in regular call series (Menzies and Tyler 1977, Blum and Menzies 1989). The six new species described here each produce advertisement calls of this type, but each is distinct from the known calls of congeners and these differences are concordant with the patterns of morphological variation documented. These calls meet the criteria for Call Guild A: "non-frequency modulated, non-pulsed simple call," or Call Guild B: "frequency modulated, non-pulsed simple call" of Emmrich et al. (2020), depending on the extent of modulation exhibited amongst species (defined as "with significant change" vs. "without significant change" by Emmrich et al. (2020).

The description of Xenorhina perexigua sp. nov. on the basis of a single specimen reflects the difficulty of detecting and capturing small, nocturnal, fossorial frogs in an inaccessible terrain, that furthermore call most frequently during torrential rain. Thus, we are unable to determine whether this species is genuinely rare or merely difficult to detect. However, it is notable that the holotype was the only individual encountered during nearly one week of survey effort at the type locality. Numerous species 
of microhylid frogs have been described from the New Guinea region on the basis of "singletons" (Allison and Kraus 2000, Günther et al. 2016). Lim et al. (2012) noted that "rare" species are common in taxonomic treatises and that additional sampling often leads only to singletons becoming "doubles," accompanied by detection of additional new species, based on singletons.

The high-rainfall belt that extends across the southern slopes and adjacent lowlands of Papua New Guinea's Central Cordillera (McAlpine et al. 1983) is proving to be a hotspot of anuran diversity (Günther and Richards 2016, 2017, 2018, 2019, 2020, Richards and Günther 2019) and our documentation of six previously undescribed frogs in the genus Xenorhina adds substantially to this already exceptional known diversity. Further studies are required to better document the distributions of these Xenorhina species. Several of them are known from only one or a handful of locations, but it is unclear whether they are genuinely range-restricted or whether their apparent rarity reflects the difficulty of conducting surveys throughout much of the region's remote and rugged landscape.

\section{Acknowledgements}

We express our gratitude to The PNG National Research Institute who assisted with the Research Visa and the PNG Department of Environment and Conservation (now Conservation and Environment Protection Authority) for approving export of specimens. Ralph Foster, Sally South, Carolyn Kovach and Mark Hutchinson provided access to material, registration numbers and numerous other courtesies at the South Australian Museum and Lisa Capon kindly produced the maps. Ken Aplin, Chris Dahl and Demas Ama assisted with specimen collections in the field. Frank Tillack (ZMB) and Elke Günther provided various technical help. Fieldwork was supported by ExxonMobil PNG Limited (EMPNG), World Wildlife Fund, Wildlife Conservation Society and Ok Tedi Mining Limited. Linda Ford (then AMNH), Carla Kishinami (BPBM), George Lenglet (then IRSNB), José Rosado (MCZ), Giuliano Doria (MSNG), Hellen Kurniati and Mumpuni (MZB), Pim Arntzen (RMNH), Miguel Vences (then ZMA) and Frank Tillack and Mark-Oliver Rödel (ZMB) kindly provided access to specimens in their care. E. Lehr, N. Poyarkov, R. Brown and an anonymous reviewer provided valuable comments that greatly improved the quality of this manuscript. We are most grateful to all of them for their support.

\section{References}

Allison A (2014) Status and diversity of the frogs of New Guinea. In: Heatwole H, Das I (Eds) Conservation biology of amphibians of Asia. Status of conservation and declines of amphibians: Eastern Hemisphere. Natural History Publications (Borneo), Kota Kinabalu, 362-382.
Allison A, Kraus F (2000) A new species of frog of the genus Xenorhina (Anura: Microhylidae) from the north coast ranges of Papua New Guinea. Herpetologica 56(3): 285-294.

Blum JP, Menzies JI (1989 [“1988”]) Notes on Xenobatrachus and Xenorhina (Amphibia: Microhylidae) from New Guinea with description of nine new species. Alytes 7(4): 125-163.

Clulow S, Swan M (2018) A complete guide to frogs of Australia. Australian Geographic, Sydney, 336 pp.

de Sá RO, Streicher JW, Selenkoyela R, Forlani MC, Loader SP, Greenbaum E, Richards SJ, Haddad CFB (2012) Molecular phylogeny of microhylid frogs (Anura: Microhylidae) with emphasis on relationships among New World genera. BMC Evolutionary Biology 12: e241. https://doi.org/10.1186/1471-2148-12-241

Emmrich M, Vences M, Ernst R, Köhler J, Barej MF, Glaw F, Jansen M, Rödel M-O (2020) A guild classification system proposed for anuran advertisement calls. Zoosystematics and Evolution 96: 515-525. https://doi.org/10.3897/zse.96.38770

Frost DR (2021) Amphibian Species of the World: an Online Reference. Version 6.1. American Museum of Natural History, New York. [Electronic Database] http://research.amnh.org/herpetology/amphibia/index.html [Accessed 19 February 2021]

Frost DR, Grant T, Faivovich J, Bain RH, Haas A, Haddad CFB, de Sá RO, Channing A, Wilkinson M, Donnellan SC, Raxworthy CJ, Campbell JA, Blotto BL, Moler PE, Drewes RC, Nussbaum RA, Lynch JD, Green DM, Wheeler WC (2006) The amphibian tree of life. Bulletin of the American Museum of Natural History 297: 1-370. https://doi.org/10.1206/0003-0090(2006)297[0001:TATOL]2.0.CO;2

Gamble T (2014) Collecting and preserving genetic material for herpetological research. Herpetological Circular 41. Society for the Study of Amphibian and Reptiles, Salt Lake City.

Günther R (2001) The Papuan frog genus Hylophorbus (Anura: Microhylidae) is not monospecific: descriptions of six new species. Russian Journal of Herpetology 8(2): 81-104.

Günther R, Knop R (2006) A new species of Xenobatrachus (Anura, Microhylidae) with a striking resemblance to Xenorhina bouwensi. Zootaxa 1268: 39-57. https://doi.org/10.11646/zootaxa.1268.1.2

Günther R, Richards SJ (2005) Two new tree-dwelling species of the genus Xenorhina from New Guinea (Anura, Microhylidae). Mitteilungen aus dem Museum für Naturkunde in Berlin. Zoologische Reihe 81(2): 167-176. https://doi.org/10.1002/mmnz.200510010

Günther R, Richards SJ (2016) Description of two new species of the microhylid genus Oreophryne (Amphibia: Anura: Microhylidae) from southern Papua New Guinea. Vertebrate Zoology 66: 157-168.

Günther R, Richards SJ (2017) Three new species of the microhylid frog genus Choerophryne (Amphibia, Anura, Microhylidae) from Papua New Guinea. Zoosystematics and Evolution 93(2): 265-279. https://doi.org/10.3897/zse.93.11576

Günther R, Richards SJ (2018) A new species of the microhylid frog genus Choerophryne from Papua New Guinea. Alytes 36: 159-169.

Günther R, Richards SJ (2019) Three new species of Austrochaperina from southern Papua New Guinea (Anura, Microhylidae). Vertebrate Zoology 69: 327-344.

Günther R, Richards SJ (2020) Two new frog species of the genus Copiula Mehely, 1901 (Anura, Microhylidae, Asterophryinae) from southern Papua New Guinea. Russian Journal of Herpetology 27: 41-53. https://doi.org/10.30906/1026-2296-2020-27-1-41-53 
Günther R, Richards SJ, Dahl C (2014) Nine new species of microhylid frogs from the Muller Range in western Papua New Guinea (Anura, Microhylidae). Vertebrate Zoology 64(1): 59-94.

Günther R, Richards SJ, Tjaturadi B (2016) A new species of the frog genus Pseudocallulops from the Foja Mountains in northwestern New Guinea (Amphibia, Microhylidae). Russian Journal of Herpetology 23(1): 63-69.

Günther R, Richards SJ, Tjaturadi B, Krey K (2020) Two new microhylid frog species of the genus Xenorhina Peters, 1863 from the Raja Ampat Islands, Indonesia. Vertebrate Zoology 70(3): 333-347. https://doi.org/10.26049/VZ70-3-2020-06

Günther R, Stelbrink B, von Rintelen T (2010) Oninia senglaubi, another new genus and species of frog (Amphibia, Anura, Microhylidae) from New Guinea. Zoosystematics and Evolution 86(2): 245-256. https://doi.org/10.1002/zoos.201000007

Hoskin CJ, Higgie M, McDonald KR, Moritz C (2005) Reinforcement drives rapid allopatric speciation. Nature 437: 1353-1356. https:// doi.org/10.1038/nature04004

Hyndman D, Menzies JI (1990) Rain Forests of the Ok Tedi headwaters, New Guinea: an ecological analysis. Journal of Biogeography 17(3): 241-273. https://doi.org/10.2307/2845122

Köhler F, Günther R (2008) The radiation of microhylid frogs (Amphibia: Anura) on New Guinea: A mitochondrial phylogeny reveals parallel evolution of morphological and life history traits and disproves the current morphology-based classification. Molecular Phylogenetics and Evolution 47: 353-365. https://oi.org/10.1016/j. ympev.2007.11.032

Köhler J, Jansen M, Rodríguez A, Kok PJR, Toledo LF, Emmrich M, Glaw F, Haddad CFB, Rödel M-O, Vences M (2017) The use of bioacoustics in anuran taxonomy: theory, terminology, methods and recommendations for best practice. Zootaxa 4251(1): 1-124. https:// doi.org/10.11646/zootaxa.4251.1.1

Kraus F (2011) New frogs (Anura: Microhylidae) from the mountains of western Papua New Guinea. Records of the Australian Museum 63(1): 53-60. https://doi.org/10.3853/j.0067-1975.63.2011.1584

Kraus F (2019) A revision of Callulops doriae (Anura: Microhylidae), with descriptions of four new species. Zootaxa 4612: 1-28. https:// doi.org/10.11646/zootaxa.4612.1.1

Kraus F, Allison A (2000) Two new species of Cophixalus from New Guinea. Journal of Herpetology 34: 535-545. https://doi. org/10.2307/1565268

Kraus F, Allison A (2002) A new species of Xenobatrachus (Anura: Microhylidae) from northern Papua New Guinea. Herpetologica 58(1): 56-66. https://doi.org/10.1655/0018-0831(2002)058[0056 :ANSOXA]2.0.CO;2

Lim GS, Balke M, Meier R (2012) Determining species boundaries in a world full of rarity: singletons, species delimitation methods. Systematic Biology 61(1): 165-169. https://doi.org/10.1093/sysbio/syr030

Mayr E (1963) Animal species and evolution. The Belknap Press of Harvard University Press, Cambridge, Massachusetts, 797 pp.

McAlpine JR, Keig G, Falls R (1983) Climate of Papua New Guinea. Australian National University Press, Canberra, 208 pp.
Meegaskumbura M, Bossuyt F, Pethiyagoda R, Manamendra-Arachchi K, Bahir M, Milinkovitch MC, Schneider CJ (2002) Sri Lanka: an amphibian hot spot. Science 298: 379-379. https://oi.org/10.1126/ science.298.5592.379

Menzies JI (2006) The frogs of New Guinea and the Solomon Islands. Pensoft, Sofia-Moscow, 345 pp.

Menzies JI, Tyler MJ (1977) Systematics and adaptations of some Papuan microhylid frogs which live underground. Journal of Zoology, London 183: 431-464. https://doi.org/10.1111/j.1469-7998.1977.tb04198.x

Oliver LA, Rittmeyer EN, Kraus F, Richards SJ, Austin CC (2013) Phylogeny and phylogeography of Mantophryne (Anura: Microhylidae) reveals cryptic diversity in New Guinea. Molecular Phylogenetics and Evolution 67: 600-607. https://doi.org/10.1016/j. ympev.2013.02.023

Peloso PLV, Frost DR, Richards SJ, Rodrigues M, Matsui M, Raxworthy CJ, Donnellan SC, Biju SD, Lemmon EM, Lemmon AR, Wheeler WC (2015) The impact of anchored phylogenomics and taxon sampling on phylogenetic inference in Narrow-mouthed Frogs (Anura, Microhylidae). Cladistics (2015): 1-28. https://doi.org/10.1111/ cla. 12118

Pethiyagoda R, Meegaskumbura M, Manamendra-Arachchi K, Schneider CJ (2014) Essay 1.2. Amphibian diversity and the case of Sri Lanka's burgeoning inventory. In: Stuart SN, Hoffmann,M, Chanson JS, Cox NA, Berridge RJ, Ramani P, Young BE (Eds) Threatened Amphibians of the World. Lynx Edicions, IUCN and Conservation International, Barcelona, 18-19.

Pyron AR, Wiens JJ (2011) A large-scale phylogeny of Amphibia including over 2800 species, and a revised classification of extant frogs, salamander, and caecilins. Molecular Phylogenetics and Evolution 61: 543-583. https://doi.org/10.1016/j.ympev.2011.06.012

Richards SJ, Günther R (2019) Three new scansorial species of microhylid frogs (Anura: Cophixalus, Oreophryne) from Papua New Guinea. Salamandra 55(2): 55-72. http://www.salamandra-journal.com

Rivera JA, Kraus F, Allison A, Butler MA (2017) Molecular phylogenetics and dating of the problematic New Guinea microhylid frogs (Amphibia: Anura) reveals elevated speciation rates and need for taxonomic reclassification. Molecular Phylogenetics and Evolution 112: 1-11. https://doi.org/10.1016/j.ympev.2017.04.008

Suwannapoom C, Sumontha M, Tunprasert J, Ruangsuwan T, Pawangkhanant P, Korost DV, Poyarkov Jr NA (2018) A striking new genus and species of cave-dwelling frog (Amphibia: Anura: Microhylidae: Asterophryinae) from Thailand. PeerJ 4422: 1-42. https://doi.org/10.7717/peerj.4422

Vieites DR, Wollenberg, EKC, Andreone F, Köhler J, Glaw F, Vences M (2009) Vast underestimation of Madagascar's biodiversity evidenced by an integrative amphibian inventory. Proceedings of the National Academy of Sciences of the United States of America 106: 8267-8272. https://doi.org/10.1073/pnas.0810821106

Zweifel RG (1972) Results of the Archbold Expeditions. No. 97. A revision of the frogs of the subfamily Asterophryinae, Family Microhylidae. Bulletin of the American Museum of Natural History 148(3): 411-546. 
Appendix 1.

Table A1. Specimens examined.

\begin{tabular}{|c|c|c|}
\hline Species & Location & Registration numbers \\
\hline $\begin{array}{l}\text { Xenorhina adisca Kraus \& Allison, } \\
2003\end{array}$ & Indonesia: Papua Province: Tembagapura & MZB Amph.8403 (holotype) \\
\hline $\begin{array}{l}\text { Xenorhina arboricola Allison \& Kraus, } \\
2000\end{array}$ & Papua New Guinea: West Sepik Province: Mt Menawa & BPBM 13747 (paratype) \\
\hline $\begin{array}{l}\text { Xenorhina arboricola Allison \& Kraus, } \\
2000\end{array}$ & Papua New Guinea: West Sepik Province: Mt Hunstein & BPBM 13745 (paratype) \\
\hline Xenorhina arndti Günther, 2010 & Indonesia: Papua Province: Bomberai Peninsula & ZMB 74629-31 (type series) \\
\hline Xenorhina bidens van Kampen, 1909 & Indonesia: Papua Province: "Digul-Fluss" & ZMA 5705 (holotype) \\
\hline Xenorhina bouwensi (De Witte, 1930) & Indonesia: West Papua Province: Arfak Mountains & $\begin{array}{l}\text { IRSNB } 1019 \text { (holotype), plus several specimens collect- } \\
\text { ed by R. Günther between 1998-2008 and stored in the } \\
\text { ZMB collection }\end{array}$ \\
\hline $\begin{array}{l}\text { Xenorhina eiponis Blum \& Menzies, } \\
1989\end{array}$ & Indonesia: Papua Province: Eipomek Valley & AMNH 128234 (paratype) \\
\hline $\begin{array}{l}\text { Xenorhina gigantea van Kampen, } \\
1915\end{array}$ & Indonesia: Papua Province: Snow Mountains & ZMA 5702 (lectotype), ZMA 5703 (paralectotype) \\
\hline $\begin{array}{l}\text { Xenorhina lanthanites (Günther \& } \\
\text { Knop, 2006) }\end{array}$ & Indonesia: Papua Province: Yapen Island & ZMB 69557-61 (type series) \\
\hline Xenorhina macrodisca & Indonesia: Papua Province: Wapoga River Headwaters & MZB Amph.10916 (holotype) \\
\hline $\begin{array}{l}\text { Xenorhina macrops van Kampen, } \\
1913\end{array}$ & Indonesia: Papua Province: Hellwig Mountains & $\begin{array}{c}\text { ZMA } 5725 \text { (lectotype), ZMA 5726-5728 (paralecto- } \\
\text { types) }\end{array}$ \\
\hline Xenorhina mehelyi (Boulenger, 1898) & $\begin{array}{l}\text { Papua New Guinea: Central Province: "Vikaiku”, Ang- } \\
\text { abunga River }\end{array}$ & MSNG 29112 (holotype) \\
\hline Xenorhina minima (Parker, 1934) & Indonesia: Papua Province: Went Mountains & ZMA 5818 (holotype), ZMA 5817 (paratype) \\
\hline Xenorhina ocellata van Kampen, 1913 & Indonesia: Papua Province: Hellwig Mountains & ZMA 5815-16 (syntypes) \\
\hline $\begin{array}{l}\text { Xenorhina ophiodon (Peters \& Doria, } \\
\text { 1878) }\end{array}$ & Indonesia: Papua Province: Hatam, Arfak Mountains & MSNG 29129 (lectotype) \\
\hline Xenorhina oxycephala Schlegel, 1858 & Indonesia: Papua Province: Triton Bay & $\begin{array}{l}\text { RMNH 2280A and 2280B (syntypes) (plus several spec- } \\
\text { imens collected by R. Günther between 1998-2008 and } \\
\text { stored in the ZMB collection) }\end{array}$ \\
\hline Xenorhina parkerorum Zweifel, 1972 & Papua New Guinea: Western Province: Imigabip & MCZ 81678 (holotype), \\
\hline Xenorhina parkerorum Zweifel, 1972 & Indonesia: Papua Province: Tenmasigin, Star Mountains & RMNH 16619 (paratype) \\
\hline $\begin{array}{l}\text { Xenorhina salawati Günther, Richards, } \\
\text { Tjaturadi \& Krey, } 2020\end{array}$ & Indonesia: West Papua Province: Salawati Island & $\begin{array}{c}\text { MZB Amph.12121-22, } \begin{array}{c}12124-26,12132,12134, \text { (type } \\
\text { series) }\end{array} \\
\end{array}$ \\
\hline $\begin{array}{l}\text { Xenorhina tillacki Günther, Richards \& } \\
\text { Dahl, } 2014\end{array}$ & Papua New Guinea: Western Province: Muller Range & SAMA R65067-68, ZMB 79532 (type series) \\
\hline Xenorhina varia & Indonesia: Papua Province: Yapen Island & ZMB 65133-37 (type series) \\
\hline $\begin{array}{l}\text { Xenorhina waigeo Günther, Richards, } \\
\text { Tjaturadi \& Krey, } 2020\end{array}$ & Indonesia: Papua Province: Waigeo Island & $\begin{array}{c}\text { MZB Amph. 12119-20, 12123, 12127-31, 12133, } \\
12155 \text { (type series) }\end{array}$ \\
\hline
\end{tabular}

